\section{Insights into neutralizing antibody responses in individuals exposed to SARS-CoV-2 in Chile}

\author{
Carolina Beltrán-Pavez ${ }^{1,2}$, Sebastián Riquelme-Barrios ${ }^{1,2}$, Aarón Oyarzún-Arrau ${ }^{1,2}$, \\ Aracelly Gaete-Argel ${ }^{1,2}$, Roxana González-Stegmaier ${ }^{3}$, Karina Cereceda-Solis ${ }^{3}$, Adam Aguirre ${ }^{3}$, \\ Dante Travisany ${ }^{4,5}$, Ricardo Palma-Vejares ${ }^{4}$, Gonzalo P. Barriga ${ }^{1,6}$, Aldo Gaggero ${ }^{1,7}$, \\ Constanza Martínez-Valdebenito ${ }^{8,9}$, Nicole Le Corre ${ }^{8,9}$, Marcela Ferrés ${ }^{8,9}$, \\ María Elvira Balcells ${ }^{10}$, Jorge Fernandez ${ }^{11}$, Eugenio Ramírez ${ }^{12}$, Franz Villarroel $^{3}$, \\ Fernando Valiente-Echeverría ${ }^{1,2}$, Ricardo Soto-Rifo ${ }^{1,2 *}$
}

\begin{abstract}
Chile has one of the worst numbers worldwide in terms of SARS-CoV-2 positive cases and COVID-19-related deaths per million inhabitants; thus, characterization of neutralizing antibody (NAb) responses in the general population is critical to understanding of immunity at the local level. Given our inability to perform massive classical neutralization assays due to the scarce availability of BSL-3 facilities in the country, we developed and fully characterized an HIV-based SARS-CoV-2 pseudotype, which was used in a 96-well plate format to investigate NAb responses in samples from individuals exposed to SARS-CoV-2 or treated with convalescent plasma. We also identified samples with decreased or enhanced neutralization activity against the D614G spike variant compared with the wild type, indicating the relevance of this variant in host immunity. The data presented here represent the first insights into NAb responses in individuals from Chile, serving as a guide for future studies in the country.
\end{abstract}

\section{INTRODUCTION}

Severe acute respiratory syndrome coronavirus 2 (SARS-CoV-2) emerged at the end of 2019 as a novel zoonotic member of the betacoronavirus genus responsible for an outbreak of severe pneumonia in Wuhan, China $(1,2)$. SARS-CoV-2 is the etiological agent of the ongoing coronavirus disease 2019 (COVID-19) pandemic, which has spread worldwide, resulting in nearly 60 million infections with close to 1.4 million deaths as per 24 November (3). The COVID-19 pandemic has devastated public health and the economies in hundreds of countries, especially in middle- and low-income countries from Latin America, including Brazil, Mexico, Perú, and Chile (4). The first SARS-CoV-2 cases in Chile were reported on 2 March 2020 (5), and since then, the country has been badly affected by the pandemic, having one of the highest rates of cases and deaths per million inhabitants worldwide (6-9).

Despite hundreds of ongoing clinical trials worldwide, Chile still had no specific therapeutic drugs or approved vaccines available, as

\footnotetext{
'SARS-CoV-2 Research Group, Virology Program, Institute of Biomedical Sciences, Faculty of Medicine, Universidad de Chile, Santiago, Chile. ${ }^{2}$ Laboratory of Molecular and Cellular Virology, Virology Program, Institute of Biomedical Sciences, Faculty of Medicine, Universidad de Chile, Santiago, Chile. ${ }^{3}$ Translational Medicine Laboratory, Fundación Arturo López Pérez Cancer Center, Santiago, Chile. ${ }^{4}$ Centro de Modelamiento Matemático UMI-CNRS 2807, Facultad de Ciencias Físicas y Matemáticas, Universidad de Chile and Fondap Center for Genome Regulation, Facultad de Ciencias, Universidad de Chile, Santiago, Chile. ${ }^{5}$ INRIA Chile Research Center, Santiago, Chile. ${ }^{6}$ Laboratory of Emerging Viruses, Virology Program, Institute of Biomedical Sciences, Faculty of Medicine, Universidad de Chile, Santiago, Chile. 'Laboratory of Environmental Virology, Virology Program, Institute of Biomedical Sciences, Faculty of Medicine, Universidad de Chile, Santiago, Chile. ${ }^{8}$ Departamento de Enfermedades Infecciosas e Inmunología Pediátricas, División de Pediatría, Escuela de Medicina, Pontificia Universidad Católica de Chile, Santiago, Chile. 'Laboratorio de Infectología y Virología Molecular, Laboratorio de Bioseguridad Nivel 3, Escuela de Medicina, Pontificia Universidad Católica de Chile, Santiago, Chile. ${ }^{10}$ Departamento de Enfermedades Infecciosas del Adulto, Escuela de Medicina, Pontificia Universidad Católica de Chile, Santiago, Chile. ${ }^{11}$ Subdepartamento de Genética Molecular, Instituto de Salud Pública, Santiago, Chile ${ }^{12}$ Sección Virus Oncogénicos, Subdepartamento de Enfermedades Virales, Instituto de Salud Pública, Santiago, Chile.

*Corresponding author. Email: rsotorifo@uchile.cl
}

of early December 2020, for the treatment and prevention of SARS$\mathrm{CoV}-2$ infections. The main goal of an effective vaccine is the induction of a specific immunological memory together with the development of neutralizing antibodies (NAbs) (10). Hence, it has been estimated that sustained population immunity ranging from 60 to $70 \%$ is required to control the COVID-19 pandemic (10). The current evidence shows that the presence of NAbs is correlated with protective immunity against a second infection with SARS-CoV-2 in nonhuman primate models $(11,12)$. Moreover, the passive transfer of NAbs limits upper and lower respiratory tract infection as well as symptomatic disease in animal models $(13,14)$, further emphasizing the relevance of NAbs in the immunity against SARS-CoV-2. However, SARS$\mathrm{CoV}-2$ induces a high degree of heterogeneity in the magnitude of adaptive immune responses, and further studies are needed to fully understand the immunity against the virus (15-19).

The $S$ protein present in the viral surface drives viral entry by recognizing the angiotensin-converting enzyme 2 (ACE2) receptor through its receptor binding domain (RBD) present in the S1 domain and is the main target for NAbs $(20,21)$. Although the viral M protein and E protein are also present at the viral surface, their functions in viral entry and/or immunogenicity are still poorly understood (22). Given its critical role in viral entry and vaccine design, much more information is available for the function and immunogenicity properties of the spike protein (23). The spike variant D614G, which emerged in February 2020 and is highly prevalent in viral sequences obtained from Europe as well as North and South America, confers increased infectivity when assessed in different pseudotyped viruses (24-30). Despite its proven role in infectivity, the impact of the $\mathrm{D}$ to $\mathrm{G}$ mutation in the neutralizing capacity of antibodies present in plasma from individuals exposed to SARS-CoV-2 requires further investigation.

Given the rapid spread of the virus in the human population and the current second wave in the Northern hemisphere, it is crucial to study the natural immunity upon exposure at the local level to characterize neutralizing activity in convalescent plasma therapy, guide 
vaccine design, and report correlations of protection in vaccine clinical trials. In this context, it is critical to establish high-throughput methods aimed to quantify NAb responses in a local setting. Although the gold standard strategy is the classic virus neutralization assay, which involves handling the isolated virus under a biosafety level 3 (BSL-3) environment, this type of facility is scarce and of limited access for academic research in Chile. However, the use of envelope-defective reporter viruses such as $\operatorname{HIV}-1(31,32)$, vesicular stomatitis virus (VSV) $(33,34)$, or murine leukemia virus (35), which can be assembled with heterologous enveloped glycoproteins (pseudotyped particles), represent safe, reliable, robust, fast, sensitive, and successful alternatives to measure NAb titers in plasma samples in a BSL-2 environment. In this work, we describe the characterization, implementation, and validation of an HIV-1-based SARS-CoV-2 pseudotype, which we used in a 96-well plate format to detect and quantify the presence of neutralizing activity in plasma or serum samples from individuals exposed to SARS-CoV-2 in Chile. By using this pseudotype, we also characterized NAb responses in four patients before and following treatment with convalescent plasma. Since the D614G virus is highly prevalent in Chile, we also assessed the ability of plasma samples to neutralize pseudotypes carrying this variant of the spike protein.

The system reported here represents an invaluable tool for the study of NAb responses against SARS-CoV-2 in the middle- and low-income setting lacking access to BSL-3 facilities. Moreover, data reported here represent the first landscape of NAb responses in individuals exposed to SARS-CoV-2 in Chile, which will help future studies aimed to understand the particular outcome of the COVID-19 pandemic in the country and in the Latin American region.

\section{RESULTS}

\section{Development and characterization of an HIV-1-based SARS-CoV-2 pseudotype to be used in a BSL-2 laboratory}

Given the minimal availability of BSL-3 facilities in Chile and the urgent need to study the immune responses in individuals exposed to SARS-CoV-2 at the local level, we looked at establishing an HIV1-based pseudotype, allowing us to characterize the NAb responses in a BSL-2 environment. For this purpose, we prepared S pseudotypes expressing firefly luciferase using either an HIV-1-based lentiviral system (three-plasmid format; see Materials and Methods) or an HIV-1- $\Delta$ Env-Luc full-length (hereafter referred as HIV-1) provirus (fig. S1A). For pseudotyping, we first used a previously described spike expression vector lacking the last 19 amino acids of the C-terminal end $(S \Delta 19)$ known to avoid retention at the endoplasmic reticulum and, thus, improving incorporation into the viral M $(36,37)$. The HIV-derived lentiviral system and the HIV-1 provirus pseudotyped with different amounts of $S \Delta 19$ were used to transduce parental human embryonic kidney (HEK) 293T cells or HEK293T cells stably expressing the SARS-CoV-2 receptor ACE2 (HEK-ACE2) (Fig. 1A and fig. S1B). We also included Huh7 cells and Vero-E6 cells, which are known to support SARS-CoV-2 replication and are commonly used to recover the virus from clinical samples $(1,2)$. Vero-E6 cells were of interest as they are known to restrict HIV-1 replication via TRIM5 $\mathrm{a}_{\mathrm{agm}}$ serving as an additional negative control (38). We observed that while the pseudotyped lentivector used here was not efficient in transducing any of the tested cells (fig. S1B), the HIV-1-based pseudotype (hereafter referred as HIV-1-SA19) was very efficient in transducing HEK-ACE2 and Huh7
A

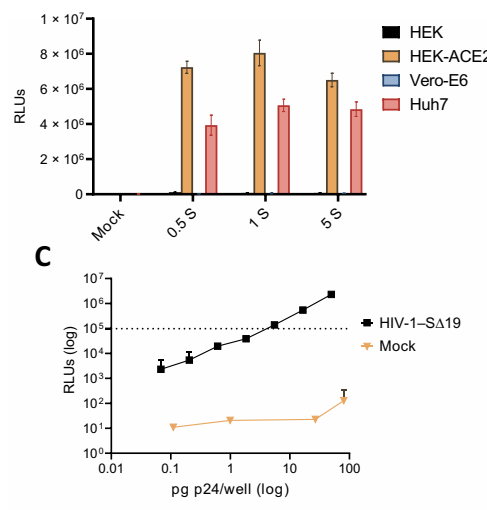

E

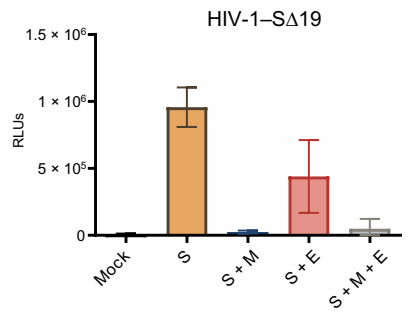

$\mathbf{F}$
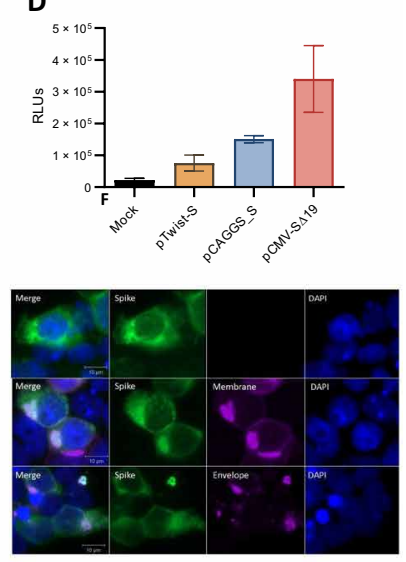

G

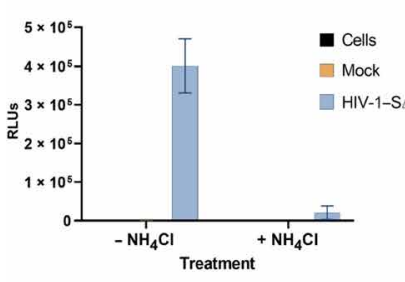

H

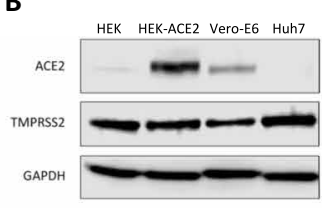

D

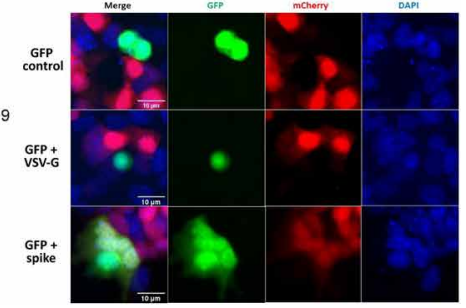

Fig. 1. Characterization of an HIV-1-based SARS-CoV-2 pseudotype. (A) Infectivity of HIV-1-S 19 pseudovirus generated with increasing amounts of SARS-CoV-2$\mathrm{S} \Delta 19$ expression plasmid. Firefly luciferase activity was measured at 48 hours after infection, and results are expressed in relative light units (RLUs) \pm percent coefficient of variation (\%CV). (B) ACE2 and TMPRSS2 expression in HEK, HEK-ACE2, Vero-E6, and Huh7 cell lines. (C) Titration of the HIV-1-S 19 pseudotype using increasing amounts of p24. (D) Infectivity of HIV-1-based pseudotypes carrying full-length $S$ protein ( $p$ Twist-S and pCAGGS-S plasmids) or $S \Delta 19$ (pCMV-S $\triangle 19$ ) in HEK-ACE2 cells. (E) Infectivity of HIV-1-S 19 pseudotypes generated in presence of $M$, E, or both expression vectors (molar ratio S:M:E of 1:0.5:0.5). (F) Subcellular localization of S:M or S:E (molar ratio of 1:0.5) in HEK cells immunostained for Flag-spike (green), Strep-tag-Membrane (magenta), or Strep-tag-Envelope (magenta). Nuclei were stained with 4',6-diamidino-2-phenylindole (DAPI; blue). (G) Inhibition of entry of SARS-CoV-2 $\mathrm{S}$ pseudotype on HEK-ACE2 by $\mathrm{NH}_{4} \mathrm{Cl}(20 \mathrm{mM})$. (H) S-mediated cell-cell fusion assay. HEK cells transiently expressing GFP together with $S \Delta 19$ or VSV glycoprotein (VSV-G) were coincubated for 5 hours with HEK-ACE2 cells expressing mCherry. Nuclei were stained with DAPI (blue). Images are representative from two independent experiments. Scale bars, $10 \mu \mathrm{m}$. GAPDH, glyceraldehyde-3-phosphate dehydrogenase; GFP, green fluorescent protein.

but not parental HEK293T and Vero-E6 cells, as expected (Fig. 1A). Notably, we observed no differences in the infectivity level of HIV1-S $\Delta 19$ despite using different amounts of the spike expression vector, suggesting that the amount of spike in the viral particle is not a limiting factor influencing viral entry of the pseudotype (Fig. 1A and fig. S1B). Analysis of ACE2 and transmembrane serine protease 2 (TMPRSS2) expression by Western blot revealed expression of both proteins in HEK-ACE2 and Vero-E6 cells (Fig. 1B). Unexpectedly, 
while high levels of TMPRSS2 were readily detected in Huh7 cells, we were not able to detect ACE2 under our experimental conditions. Similar results were reported by Liao and colleagues (39), raising the possibility of an ACE2-independent entry of SARS-CoV-2 in this cell type. Therefore, we decided to use HEK-ACE2 cells to characterize and optimize the HIV-1-S $\Delta 19$ pseudotype. The relative light units (RLUs) obtained with different amounts of HIV-1-S $\Delta 19$ [as measured by anti-p24 enzyme-linked immunosorbent assay (ELISA)] showed a wide linear range, which was several logs higher than the HIV-1 provirus lacking a surface glycoprotein (Fig. 1C). This linear range was not affected by decreasing the volume of the luciferase reagent for detection, allowing us to reduce the cost of the assay (fig. $\mathrm{S} 1 \mathrm{C})$. We also observed that storage at $-80^{\circ} \mathrm{C}$ in $50 \%$ fetal bovine serum results in a minimal loss of infectivity, indicating that HIV1-S $\Delta 19$ preparations can be stored for further use (fig. S1D).

We then tested the impact of using different spike-expressing vectors on the ability of the HIV-1-S $\Delta 19$ pseudotype in transducing susceptible cells. Consistent with a decreased endoplasmic reticulum retention, HIV-1 pseudotyped with the $\mathrm{S} \Delta 19$ version of spike was more efficient than pseudotypes containing the full-length protein (expressed from pTwist and pCAGGS vectors) in infecting HEK-ACE2 cells (Fig. 1D). Since the $M$ and $E$ proteins are components of the SARS-CoV-2 surface, we then wanted to evaluate whether these viral proteins have an impact on HIV-1-S $\Delta 19$ infectivity. We observed that inclusion of $\mathrm{M}, \mathrm{E}$, or both strongly interferes with infectivity when used at an S:M:E molar ratio of 1:0.5:0.5 with $\mathrm{M}$ being the most potent inhibitor (Fig. 1E). This negative effect of $\mathrm{M}$ and $\mathrm{E}$ proteins on infectivity was not exclusive for the $\mathrm{S} \Delta 19$ version of the spike protein as it was also observed with full-length $S$ carrying the reference sequence or the D614G mutation (fig. S1E). Reduction of the coexpressed levels of $\mathrm{M}$ and $\mathrm{E}$ using an S:M:E molar ratio of 1:0.1:0.1 relieved the negative effect of $\mathrm{E}$ but maintained the strong negative effect of $\mathrm{M}$ (fig. S1F). Immunostaining analyses revealed that $S$ colocalizes and accumulates with $M$ in the cytoplasm (Fig. 1F), which must be related to the M-mediated retention of $S$ at the endoplasmic reticulum-Golgi intermediate compartment (ERGIC) previously reported for the SARS-CoV proteins (40). An alternative possibility could be related to the recently described egress pathway used by $\beta$-coronaviruses, which occurs via deacidified lysosomes and therefore may impede the trafficking of the spike protein to the HIV-1 assembly sites at the plasma membrane (41).

Considering that it was not possible to include $\mathrm{M}$ and $\mathrm{E}$ together with $\mathrm{S}$ in the HIV-1-S $\Delta 19$ pseudotype, we then sought to evaluate whether the $\mathrm{S} \Delta 19$ alone was sufficient to drive entry by endocytosis and fusion as it occurs with the wild-type virus (21). For this, we first evaluated the impact of the endocytosis inhibitor $\mathrm{NH}_{4} \mathrm{Cl}$ and observed that infectivity of the HIV-1-S $\Delta 19$ pseudotype was indeed blocked (Fig. $1 \mathrm{G}$ ). We then assessed the ability of the $\mathrm{S} \Delta 19$ alone to drive cell-to-cell fusion. For this, we cocultured parental HEK cells previously cotransfected with the expression vector for S $\Delta 19$ [VSV glycoprotein (VSV-G) was used as a control] and d2EGFP together with HEK-ACE2 cells previously transfected with an mCherryexpressing vector. We observed that expression of S $\Delta 19$ but not VSV-G in green fluorescent protein (GFP)-expressing HEK cells drives fusion with mCherry-expressing HEK-ACE2 cells (Fig. 1H) with an increment in the size of the $\mathrm{GFP}^{+}$foci (reaching up to seven nuclei per foci) due to the formation of multinucleated bodies when HEKACE2 and HEK-S $\triangle 19$ were present. No fusion between HEK cells was observed even under expression of $\mathrm{S} \Delta 19$, indicating that fusion is dependent on the S $\Delta 19$-ACE2 interaction (Fig. $1 \mathrm{H}$ and fig. S1G). Together, these data indicate that the HIV-1-S $\Delta 19$ pseudotype fully recapitulates the most relevant aspects of the spike-mediated entry of SARS-CoV-2 in ACE2-expressing cells and can be used for the detection and titration of NAbs.

\section{Detection and titration of NAbs in clinical samples from individuals exposed to SARS-CoV-2 in Chile}

Since a potent NAb response is critical for conferring protective immunity against SARS-CoV-2, we then sought to evaluate the performance of the HIV-1-S $\Delta 19$ pseudotype in neutralization assays in a 96-well plate format using clinical samples from individuals exposed to SARS-CoV-2 in Chile. For this, we first compared the performance of our pseudotype with the classical neutralization assays using the whole SARS-CoV-2 virus standardized in two different laboratories in the country. As observed, we obtained Pearson correlations of $0.5502(P=0.1576$; fig. S2A $)$ and $0.9026(P=0.0003$; fig. $\mathrm{S} 2 \mathrm{~B})$, depending on the laboratory in which the classical neutralization assay was carried out, indicating that our HIV-1-S $\Delta 19$ pseudotype is a convenient tool for the massive characterization of NAb responses in Chile.

We then performed NAb titration curves using serum samples from 38 healthy donors obtained both before ( $n=20$, pre-COVID-19) and during the COVID-19 pandemic [ $n=18$, polymerase chain reaction-negative $\left(\mathrm{PCR}^{-}\right)$] as well as from SARS-CoV-2-diagnosed patients who were either recovered from the disease $(n=21)$ or actively sick $(n=19)$. Previous determination of anti-SARS-CoV-2 RBD immunoglobulin G (IgG) by ELISA showed variable levels among patients ranging from 0.1 to $39.4 \mu \mathrm{g} / \mathrm{ml}$ (Fig. 2A and Table 1). We observed that none of the samples from the healthy donors presented specific neutralizing responses characterized by a sigmoidal curve in the titration assay (Fig. $2 \mathrm{~B}$, see pre-COVID and $\mathrm{PCR}^{-}$). However, some samples presented a low background of around $30 \%$ of nonspecific neutralization (pre-COVID group), with a higher nonspecific inhibition in the $\mathrm{PCR}^{-}$group, which presented one sample reaching $60 \%$ of neutralization at low dilutions (Fig. $2 B$ ). Since we were not able to identify a neutralizing response in samples from the healthy groups being not able to calculate a median inhibitory dose 50 (ID50) value, all of them were considered as negative for neutralization using the HIV-1-S $\Delta 19$ pseudotype.

Regarding the samples corresponding to the recovered and active sick groups, we observed sigmoidal curves with dose-response inhibition in most samples indicating specific neutralizing responses against the spike protein. In the case of recovered volunteers, $100 \%$ of them presented neutralizing activity, while $88.8 \%$ of the active sick group showed neutralization (Fig. 2B). To discard any nonspecific inhibition and confirm the presence of NAbs targeting the spike protein and not the other component of the pseudotype, we then looked at the specificity of some samples from the active sick and recovered groups by comparing the effects of a 1:320 dilution on HIV-1-VSV-G and HIV-1-S $\Delta 19$ pseudotypes (fig. S2C). As expected, we observed that samples from the individuals exposed to SARS-CoV-2 were unable to neutralize HIV-1VSV-G, indicating that the neutralizing activity detected against the HIV-1-S $\Delta 19$ pseudotype confers specific neutralization against the $S$ protein.

Titration curves of the samples presenting neutralizing activity revealed a broad range of NAb titers with ID50 values ranging between 214.5 and 29,736 (Fig. 2B and Table 1). A correlation analysis 
A

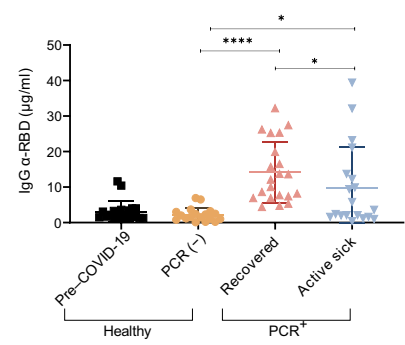

B
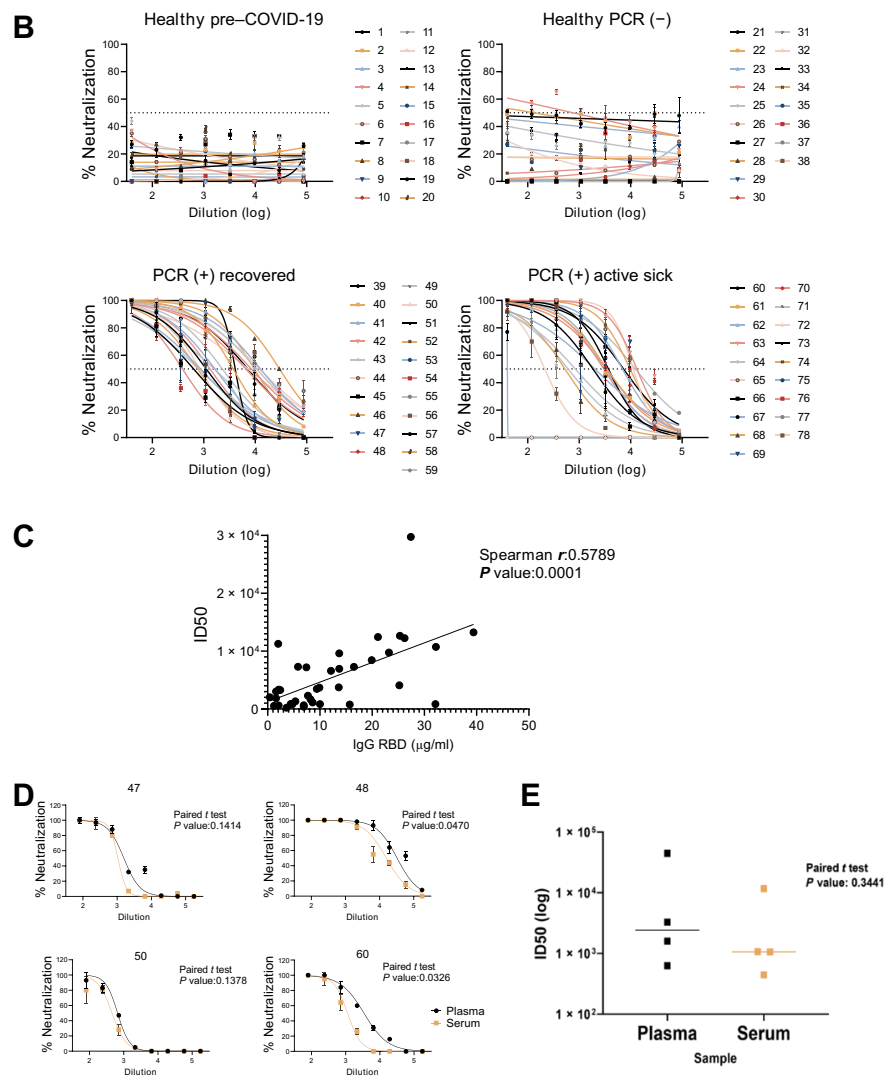

Fig. 2. Measurement of neutralizing activity in samples from volunteers using the HIV-1-S $\Delta 19$ pseudotype. Plasma or serum samples were collected from prepandemic volunteers, SARS-CoV-2 $\mathrm{PCR}^{-}$healthy donors, and $\mathrm{PCR}^{+}$recovered and actively sick patients. (A) Absolute quantification of IgG anti-spike RBD ELISA. (B) Neutralization curves of HIV-1-S 19 pseudotype in serum/plasma samples. Samples were titrated in triplicate at serial threefold dilutions $(1: 40$ to $1: 87,480)$ and are expressed as percent of neutralization $\pm \% C V$. Statistical differences between volunteers or patient groups were assessed by Wilcoxon-Mann-Whitney $t$ test. (C) Spearman's rank correlation between ID50 and anti-RBD ELISA absolute quantification $(\mu \mathrm{g} / \mathrm{ml})$ in the total samples analyzed. (D) Titration of neutralization activity using paired plasma and serum samples from four donors. Statistical differences in paired samples were calculated by Paired $t$ test. (E) ID50 differences between plasma and serum samples. Each dot represents an individual. Statistical comparison was calculated by Paired $t$ test. For all statistical tests, $P$ values below 0.05 were considered statistically significant. ${ }^{*} P<0.05$ and ${ }^{* * *} P<0.0001$.

between the levels of anti-RBD IgG and the corresponding ID50 of each sample revealed a significant positive correlation (Spearman $r=0.5789, P=0.0001$; Fig. 2C). Although further analyses including additional samples is undoubtedly required, these data show the presence of specific NAbs in 95\% (38 of 40) of the recovered and actively sick patients in our study population, with nonstatistical differences among ID50 within groups (Mann-Whitney $U$ test $P=0.9307$ ). Thus, the present pilot analysis suggests a high percentage of individuals exposed to SARS-CoV-2 in Chile present anti-spike NAbs.

We also used the HIV-1-S $\Delta 19$ pseudotype to characterize the $\mathrm{NAb}$ responses in convalescent plasma donors and to determine whether the nature of the sample (plasma or serum) could have an impact in the calculation of the corresponding ID50 value. For this, we performed NAb titration using four plasma samples together with their cognate serum samples obtained from convalescent individuals. Titration curves showed variable ID50 titers of NAbs in the samples ranging from 467 to 29,595 (Fig. 2D). While intrapatient analyses revealed significant differences in the calculated ID50 in two of four (paired $t$ test) samples with higher ID50 values obtained with plasma, no such differences were observed when the whole dataset was analyzed together, indicating that plasma or serum should be used indistinctly for NAb measurements (Fig. 2E). Together, these data support the suitability, specificity, and accuracy of the HIV$1-S \Delta 19$ pseudotype to perform screening and titration of NAb responses in plasma or serum samples from individuals exposed to SARS-CoV-2.

\section{Impact of the D614G variant of the spike protein on the susceptibility to NAbs}

It has been widely reported that the D614G variant of S protein confers increased infectivity when assessed in different pseudotyped viruses $(25,27-30,42)$. By using monoclonal antibodies or convalescent plasma, these studies have also reported that this mutation does not alter the susceptibility to NAbs, although this last concept was recently challenged (24). Considering that $83 \%$ of SARS-CoV-2 sequences obtained from Chile until 24 November 2020 correspond to the D614G variant (Fig. 3A), we wanted to evaluate whether this amino acid change has an impact on the susceptibility to NAbs. Consistent with previous reports, comparisons between the two spike variants reveal a fivefold increase in infectivity for the G614 variant (Fig. 3B). Notably, the G614 variant also conferred increased infectivity when compared to the $\mathrm{S} \Delta 19$ variant, which carries an aspartic acid at position 614, indicating that the relief of endoplasmic reticulum retention conferred by the $\Delta 19$ deletion is not the major constraint that must be circumvented by the spike protein at least in cell culture (Fig. 3B).

We then used equal amounts of HIV-1-S 19 (D614) and HIV1-S-G614 pseudotypes (3 pg of p24 determined by ELISA) to perform a side-by-side calculation of the ID50 values using samples from actively sick and recovered individuals (Fig. 3C and Table 2). Individual analyses of the ID50 obtained for each plasma sample revealed changes in the neutralizing activity in $36.8 \%$ (14 of 38) of the samples tested. Hence, analysis of the whole dataset indicates significant differences to neutralization between both spike variants $(P=0.0024$; Fig. 3D). We identified that $31.6 \%$ of the samples $(12$ of $38)$ presented a significant decrease in their ability to neutralize the pseudotype carrying the D614G variant and 5.3\% (2 of 38) of the samples contained NAbs targeting more potently the pseudovirus containing this highly prevalent spike variant (Fig. 3E and Table 2).

Although it was not possible to determine which variant of the virus infected these patients, our data indicate that the D614G mutation not only confers increased infectivity to the pseudotype but also is able to affect the susceptibility to NAbs present in plasma samples from individuals exposed to SARS-CoV-2. 
Table 1. Neutralizing activity in the study population. $\mathrm{Cl}$, confidence interval; -, not determined; d.p.r, days post recovery; d.p.s., days post symptoms; $R^{2}$, goodness of fit $R$ square of nonlinear regression; <160: non-neutralizing samples (neutralizing assay cutoff); ID, inhibitory dilution.

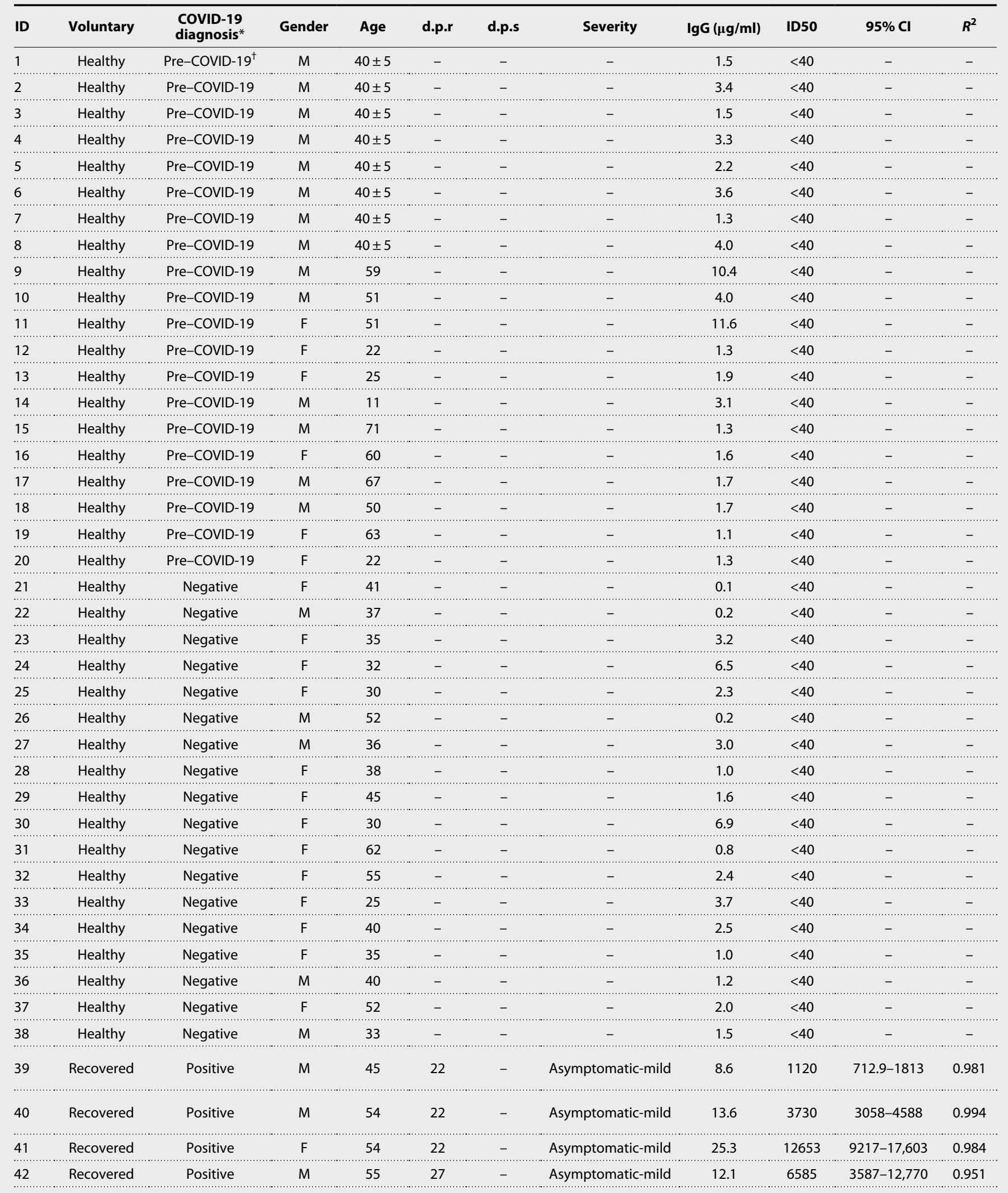

continued to next page 


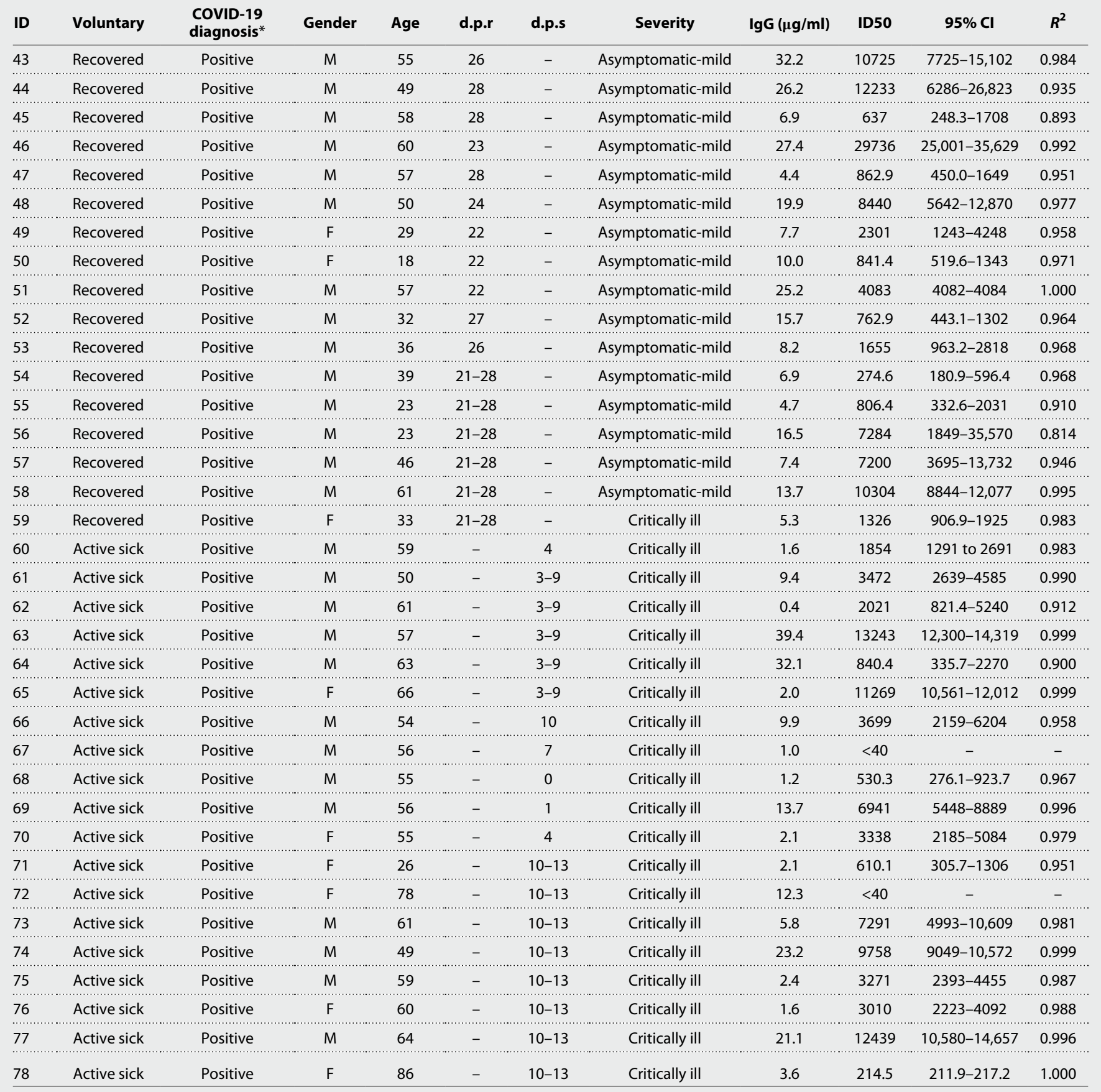

*Diagnosis by SARS-CoV-2 real-time reverse transcription PCR. $\quad$ †Plasma samples collected before October 2019 correspond to pre-COVID-19.

\section{Characterization of $\mathrm{NAb}$ responses in patients treated with convalescent plasma}

Considering that treatment with convalescent plasma appears as an attractive potential therapeutic option to decrease severity in patients with severe COVID-19 (43), we lastly used the HIV-1-S $\Delta 19$ pseudotype to determine the NAb responses in four patients treated with convalescent plasma in the context of the Fundación Arturo López Pérez (FALP)-COVID clinical trial (44). All these patients were treated no more than 14 days after diagnosis and presented variable levels of anti-RBD IgG at the moment of treatment (Fig. 4A). Analyses of the titration curves before and after treatment showed very interesting differences among these patients (Fig. 4B). For instance, while patient 3 presented very low levels of NAb before treatment (ID50 $=170$ ), patients 1,2 , and 4 presented high levels of NAbs before plasma transfusion (ID50 $=2944$, 6493, and 10,720, respectively; Fig. 4C). Moreover, while patient 1 presented a sevenfold increase in the NAb titers upon treatment 


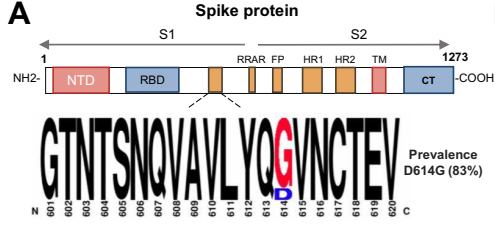

C

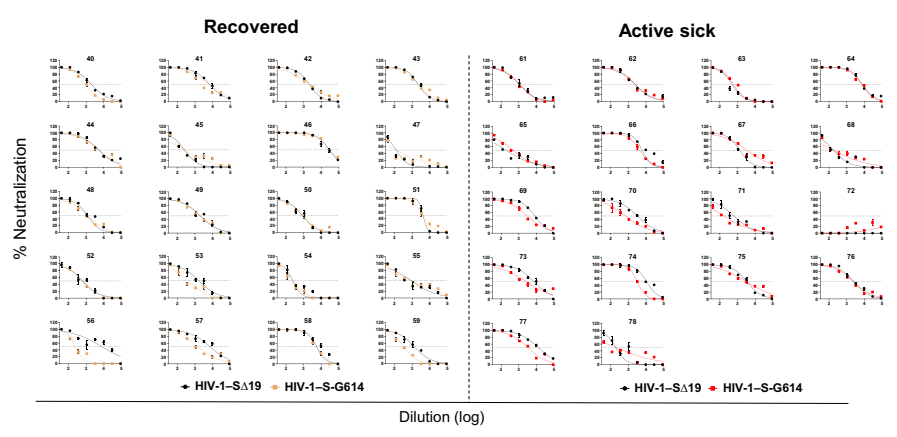

D

$E$
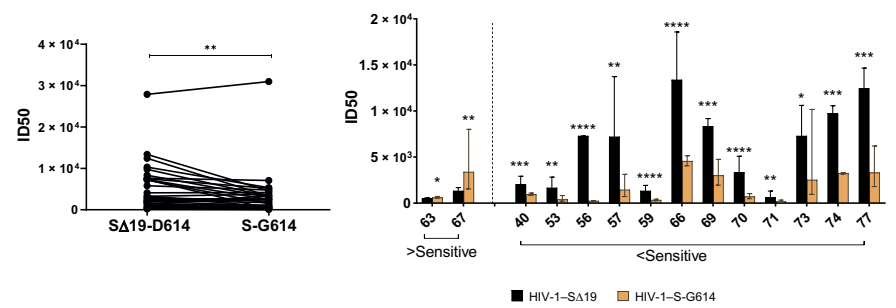

Fig. 3. Impact of the G614 spike variant on neutralizing activity in samples from individuals exposed to SARS-CoV-2 in Chile. (A) Schematic representation of the SARS-CoV-2 spike protein and frequency plot of D/G variant at the 614 position in 228 SARS-CoV-2 genomes sequenced in Chile. NTD, N-terminal domain; FP, fusion peptide; HR1 and HR2, heptad-repeat region 1 and 2, respectively; TM, transmembrane region; CT, cytoplasmic tail. (B) Infectivity of HIV-1 pseudotyped with full-length S (D614), S 19 (D614), and full-length S (G614). Results are expressed in relative light units (RLU) $\pm \% C V$ and correspond to a representative assay performed in triplicate. (C) Impact of D614 or G614 mutation in neutralization activity of serum samples of HIV-1-based pseudovirus. Neutralizing curves were performed to calculate ID50 titers. Results are expressed as percent of neutralization $\pm \% C V$ and correspond to a representative assay performed in triplicate. (D) ID50 comparison between samples tested with S $\Delta 19-$ D614 and S-G614 pseudovirus by Welch's $t$ test. (E) Serum samples with significant differences in sensitivity to neutralization by both $\mathrm{S}$ variants. Error bars indicate asymmetrical confidence intervals (profile likelihood intervals) $95 \% \mathrm{Cls}$. Statistical differences were calculated by extra sum-ofsquares $F$ test. $P$ values below 0.05 were considered statistically significant. ${ }^{*} P<0.05$, ${ }^{* *} P<0.01$, ${ }^{* *} P<0.001$, and ${ }^{* * * *} P<0.0001$.

(from ID50 $=2944$ to 20,908; $F$ test $P<0.0001$ ), no significant changes were observed in patient 4 (Fig. $4 \mathrm{C}$ ). Besides, while patient 3 presented a 12.3-fold increase in its NAb titer (from ID50 = 170 to 2100 ; $F$ test $P<0.0001$ ), this titer remained lower when compared to the other three patients (Fig. 4C). Although these data represent a minimal view of the ongoing clinical trial and the analysis of additional patients are undoubtedly required to perform robust conclusions, these data suggest that despite high levels of NAb before treatment, convalescent plasma transfer can induce an increase in the NAb titers in some patients. Together, these results show the versatility of the HIV1-S $\Delta 19$ pseudotype to perform studies of NAb responses including intrapatient follow-up studies in individuals receiving convalescent plasma treatment.

\section{DISCUSSION}

The COVID-19 pandemic has devastated the economies and public health of many countries, and Chile has not been an exception. With more than 500 thousand reported cases and more than 15,000 reported deaths for a country with a population of 18 million, Chile leads the numbers in terms of cases and deaths per million inhabitants worldwide. Unfortunately, our scientific community faces an important problem related to the scarce availability of environments with a BSL-3 in the country, which are required for the isolation and characterization of viral strains obtained from clinical samples and to perform basic research on this new pathogen. The lack of massive access to such an infrastructure impedes our advancement in understanding the pandemic at the local level, for example, in studies related to NAb responses in individuals exposed to SARS-CoV-2. This prompted us to develop, characterize, and optimize a two-plasmid HIV-1-based pseudotype that recapitulates the most relevant steps of the ACE2-dependent S-mediated cell entry. This pseudotype was robust, accurate, specific, and, more importantly, easy to implement, avoiding the requirement of a BSL-3 facility. By using this pseudotype, we were able to provide the first insights into the NAb responses using clinical samples from individuals exposed to SARS-CoV-2 living in Chile. We also provided data on NAb responses in actively sick patients before and after treatment with convalescent plasma.

During pseudotype optimization and considering that the $\mathrm{M}$ and E proteins accompany the spike protein in the SARS-CoV-2 membrane, we included these surface proteins during HIV-1-S $\Delta 19$ preparation. However, we observed a strong inhibition of the infectivity at two different S:M:E molar ratios with $\mathrm{M}$ being the most potent inhibitor. Since $\mathrm{M}$ and $\mathrm{E}$ were shown to participate in the assembly of SARS-CoV particles at the endoplasmic reticulum and the $M$ protein retains $S$ at the ERGIC compartment (40), we strongly believe that the inhibitory effect of SARS-CoV-2 M and, possibly, E are related to the intracellular trafficking of the spike protein as described for SARS-CoV. These observations are consistent with our immunostaining data showing intracellular accumulation of SARS-CoV-2 M and S. Although it is unclear whether SARS-CoV-2 M and E proteins have immunogenicity in humans, a preclinical study of an S:M:E virus-like particle (VLP) mRNA vaccine showed the lack of antibody responses against $M$ and $E$ in mice (45). Despite the fact that it was not possible to assemble an HIV-1 particle pseudotyped with $S, M$, and E, we showed that the $S \Delta 19$ protein alone was sufficient to fully drive ACE2-dependent entry through endocytosis and fusion, allowing the use of the HIV-1-S $\Delta 19$ pseudotype in the study of NAb responses in different clinical samples.

Considering the high prevalence of the D614G spike variant in Chile (https://cov2.cl), we wanted to know whether antibodies present in clinical samples from actively sick and recovered patients were more potent in neutralizing the pseudotype carrying this mutation. However, while we observed that the highly predominant D614G variant of the spike protein conferred increased infectivity to the pseudotype, we also observed that this occurred, altering the susceptibility to NAbs from some plasma samples. Hence, we identified two plasma samples having a significant increase in their neutralizing activity against the pseudotype carrying the D614G variant, but more importantly, we identified 12 of 38 samples having a significant reduction in their neutralization capacity against this predominant variant. These data provide further evidence for the relevance of the D614G mutation in the immune response, raising the possibility for the generation of NAbs targeting specific antigenic 
Table 2. Differences in neutralizing activity of D614 or G614 variant pseudotype in COVID-19 volunteers. -, not applicable.

\begin{tabular}{|c|c|c|c|c|c|c|c|c|}
\hline ID & Voluntary & ID50 D614 & $95 \% \mathrm{Cl}$ & $R^{2}$ & ID50 G614 ${ }^{\dagger}$ & $95 \% \mathrm{Cl}$ & $R^{2}$ & $P^{\ddagger}$ \\
\hline 40 & Recovered & 2014 & $1409-2915$ & 0.983 & 961.1 & $846.3-1091$ & 0.9977 & 0.0003 \\
\hline 41 & Recovered & 7479 & $6426-8706$ & 0.997 & 5179 & $2786-9610$ & 0.9876 & 0.0811 \\
\hline 42 & Recovered & 1976 & $1740-2244$ & 0.998 & 2421 & $1547-3846$ & 0.9745 & 0.2644 \\
\hline 43 & Recovered & 2649 & $2208-3173$ & 0.995 & 2643 & $1808-3891$ & 0.9822 & 0.9889 \\
\hline 44 & Recovered & 5819 & $3282-10,975$ & 0.952 & 4772 & 2558-9103 & 0.9528 & 0.5845 \\
\hline 45 & Recovered & 216.9 & $113.8-423.6$ & 0.933 & 357.5 & $116.7-981.6$ & 0.8744 & 0.3277 \\
\hline 46 & Recovered & 27,899 & $25,861-30,029$ & 0.999 & 30,973 & $24,058-40,697$ & 0.9818 & 0.3904 \\
\hline 47 & Recovered & 158.2 & $118.2-211.8$ & 0.991 & 76.25 & $0.1199-360.2$ & 0.6711 & 0.2845 \\
\hline 48 & Recovered & 1365 & $965.2-2005$ & 0.992 & 1045 & $648.4-1706$ & 0.9699 & 0.3155 \\
\hline 49 & Recovered & 2301 & $1243-4248$ & 0.958 & 1724 & $1121-2654$ & 0.9786 & 0.3662 \\
\hline 50 & Recovered & 841.4 & $519.6-1343$ & 0.971 & 839.1 & $564.8-1249$ & 0.9784 & 0.665 \\
\hline 51 & Recovered & 4083 & $4082-4084$ & 1 & 4172 & $3685-4737$ & 0.9975 & 0.6567 \\
\hline 52 & Recovered & 762.9 & $443.1-1302$ & 0.964 & 521.7 & $401.6-679.0$ & 0.9901 & 0.1411 \\
\hline 53 & Recovered & 1655 & $963.2-2818$ & 0.968 & 402.5 & $199.8-822.8$ & 0.9353 & 0.0022 \\
\hline 54 & Recovered & 274.6 & $180.9-596.4$ & 0.968 & 210.5 & $156.7-284.8$ & 0.9819 & 0.2327 \\
\hline 55 & Recovered & 806.4 & $332.6-2031$ & 0.91 & 1067 & $344.3-3239$ & 0.8704 & 0.6335 \\
\hline 56 & Recovered & 7284 & $1849-35,570$ & 0.814 & 237.6 & $209.9-269.9$ & 0.9973 & $<0.0001$ \\
\hline 57 & Recovered & 7200 & $3695-13,732$ & 0.946 & 1453 & $717.1-3119$ & 0.9369 & 0.0023 \\
\hline 58 & Recovered & 10,304 & $8844-12,077$ & 0.995 & 5336 & $3555-8146$ & 0.999 & 0.7095 \\
\hline 59 & Recovered & 1326 & 906.9-1925 & 0.983 & 330.8 & $255.4-427.9$ & 0.9887 & $<0.0001$ \\
\hline 61 & Active sick & 1299 & $828.9-2061$ & 0.972 & 935.4 & $717.4-1222$ & 0.9904 & 0.147 \\
\hline 62 & Active sick & 2307 & $1402-4105$ & 0.967 & 2639 & $1534-4704$ & 0.9623 & 0.6693 \\
\hline 63 & Active sick & 497.8 & $423.0-584.3$ & 0.998 & 612.2 & $522.5-721.9$ & 0.9991 & 0.0366 \\
\hline 64 & Active sick & 7641 & $6481-9043$ & 0.994 & 7075 & $5480-9122$ & 0.9901 & 0.5425 \\
\hline 65 & Active sick & 189 & $47.16-521.5$ & 0.859 & 458.3 & $269.2-776.9$ & 0.9642 & 0.075 \\
\hline 66 & Active sick & 13,380 & $9740-18,574$ & 0.983 & 4560 & $4062-5145$ & 0.9989 & $<0.0001$ \\
\hline 67 & Active sick & 1330 & $1052-1685$ & 0.992 & 3388 & $1548-8004$ & 0.9264 & 0.0094 \\
\hline 68 & Active sick & 131.8 & $106.7-156.7$ & 0.995 & 369.9 & $16.90-1815$ & 0.7161 & 0.17 \\
\hline 69 & Active sick & 8338 & $7582-9180$ & 0.998 & 3011 & 1949-4749 & 0.974 & 0.0002 \\
\hline 70 & Active sick & 3338 & $2185-5084$ & 0.979 & 711.3 & $487.1-1037$ & 0.9821 & $<0.0001$ \\
\hline 71 & Active sick & 610.1 & $305.7-1306$ & 0.951 & 170.5 & $75.69-327.1$ & 0.9279 & 0.0069 \\
\hline 72 & Active sick & $<40$ & - & - & $<40$ & - & - & - \\
\hline 73 & Active sick & 7291 & $4993-10,609$ & 0.981 & 2524 & $946.6-10,169$ & 0.8913 & 0.0261 \\
\hline 74 & Active sick & 9758 & $9049-10,572$ & 0.999 & 3236 & $3156-3321$ & 0.9999 & 0.0009 \\
\hline 75 & Active sick & 3271 & 2393-4455 & 0.987 & 3747 & $1831-7965$ & 0.9405 & 0.6572 \\
\hline 76 & Active sick & 3010 & $2223-4092$ & 0.988 & 2046 & $1400-3021$ & 0.9808 & 0.0767 \\
\hline 77 & Active sick & 12,439 & $10,580-14,657$ & 0.996 & 3310 & $1796-6203$ & 0.9542 & 0.0003 \\
\hline 78 & Active sick & 214.5 & $211.9-217.2$ & 1 & 99.92 & $0.1495-549.8$ & 0.6717 & 0.2666 \\
\hline
\end{tabular}

*D614 variant corresponds to HIV-1-S 19 pseudotype. $\quad$ †G614 variant corresponds to HIV-1-S-G614 (full-length spike) pseudotype. $\quad$ ‡Extra sum-of-squares $F$ test.

epitopes of this predominant variant and for an immune escape that requires further investigation.

An interesting observation from our analyses is the good correlation between the levels of total anti-RBD IgG against SARS-CoV-2 measured by ELISA and the NAb titers in samples from the active sick and recovered groups, as previously described (46). Notably, studies aimed to measure NAbs in individuals exposed to SARSCoV-2 have demonstrated different results depending on the location. For instance, a study performed on 149 samples from convalescent individuals from New York City revealed that $33 \%$ of the patients have NAbs with ID50 less than 1:50, while 79\% presented NAbs with ID50 below 1:1000, and only $1 \%$ showed titers above 
A

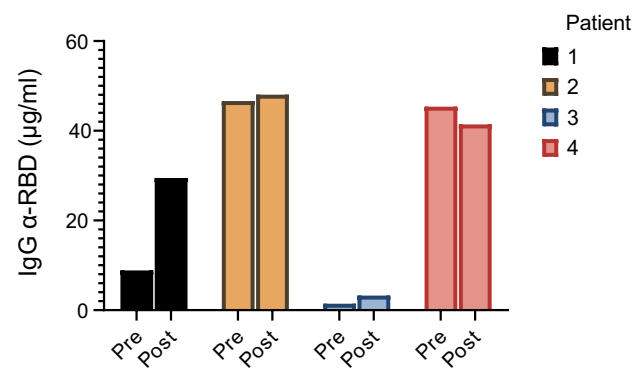

B
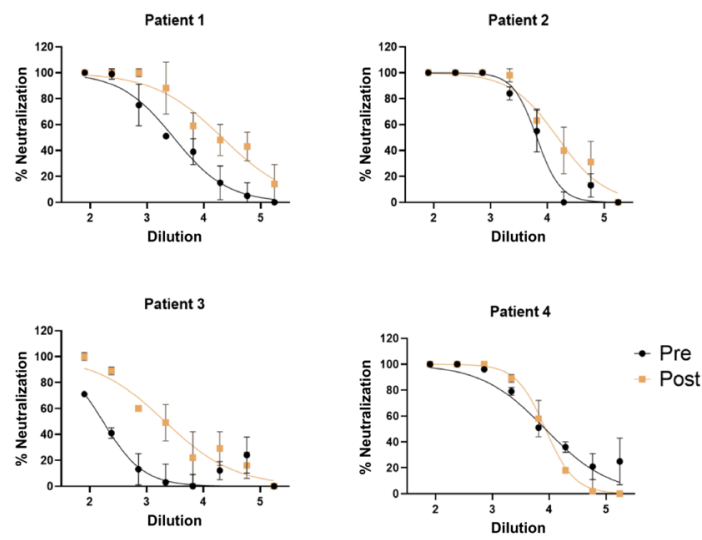

C

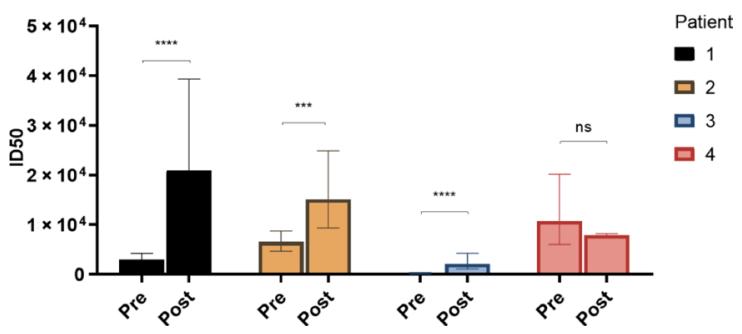

Fig. 4. Convalescent plasma transfer induces an increase in the NAb titers in some patients. (A) Absolute quantitation of $\lg G \alpha$-RBD in SARS-CoV- 2 S protein by ELISA. (B) NAb titration curves of serum from patients before (pre) and after (post) transfusion. Results are expressed as percent of neutralization $\pm \% C V$ as described in Materials and Methods and correspond to a representative assay performed in triplicate. (C) ID50 value comparison between serum samples pre- and post-convalescent plasma transfusion. Error bars indicate asymmetrical confidence intervals (profile likelihood intervals) $95 \% \mathrm{Cls}$. Statistical differences were calculated by extra sum-of-squares $F$ test. $P$ values below 0.05 were considered statistically significant. ${ }^{*} P<0.05,{ }^{*} P<0.01,{ }^{* *} P<0.001,{ }^{* * *} P<0.0001$. ns, nonsignificant.

1:5000 (43). Another study carried out in Shanghai analyzed 175 plasma samples and reported high variations in the NAb titers with ID50 values ranging from below the limit of detection (ID50 < 40) and ID50 of 21,567 . In this study, $17 \%$ of the patients presented medium-low titers of NAbs (ID50 $=500$ to 999 ), $39 \%$ presented medium-high titers (ID50 $=1000$ to 2500 ), and $14 \%$ presented high titers (ID50 > 2500), with only two patients presenting very high NAb titers $(15,989$ and 21,567) (47). Among the samples analyzed in our study obtained from actively sick and recovered patients, we observed NAb titers with ID50 values between 214.5 and 29,736 in 38 of 40 samples and ID50 $<160$ (considered as negative) in the two remaining samples. From the samples containing NAbs, $21.1 \%$ had ID50 titers between 500 and 999 (8 of 38), 15.8\% had ID50 titers between 1000 and 2500 (6 of 38), and 57.9\% had ID50 titers above
2500 (22 of 38). From these, 15 patients (39.5\%) presented very high titers with ID50 values above 5000 suggesting a potent NAb response in these individuals. Although we identified some degree of unspecific neutralization in samples from the healthy group that can be attributed to the presence of cross-reactive NAbs against seasonal coronavirus as recently described (48), none of these samples presented a dose-response sigmoidal curve, as observed in the recovered and active sick groups. These data further stress the critical relevance of performing local characterizations of the immune responses in individuals exposed to SARS-CoV-2. This is particularly important, for example, when evaluating the suitability of convalescent plasma treatment or when analyzing the efficacy of vaccine candidates in phase 3 clinical trials. Recent studies revealed the relevance of the early use of convalescent plasma containing high $\mathrm{NAb}$ titers as a therapeutic option for patients with COVID-19 (49-52).

Given the robustness, accuracy, and specificity of the HIV-1S $\Delta 19$ pseudotype, we are currently supporting two clinical trials carried out in the country (NCT04384588 and NCT04375098), which are intended to evaluate the use of convalescent plasma in patients with active COVID-19. We have also established collaborations with other research laboratories in Chile and South and Central America to share the pseudotype and cell lines. The HIV-1-S $\Delta 19$ pseudotype will also be helpful to support follow-up studies of immunity in individuals exposed to SARS-CoV-2, which are currently in process in Chile.

Last but not least, Chile has agreements to participate in at least three phase 3 vaccine clinical trials. Therefore, the HIV-1-S $\Delta 19$ pseudotype characterized here will be useful for the fast and accurate characterization of NAb responses upon vaccination.

\section{MATERIALS AND METHODS Cell culture and plasmids}

HEK293T [National Institutes of Health (NIH) AIDS Reagent Program], Vero-E6 (provided by N. Tischler, Fundación Ciencia y Vida, Chile), and Huh7 (provided by M. Ferrés, Pontificia Universidad Católica de Chile, Chile) cells were maintained in Dulbecco's Modified Eagle Medium (DMEM) (Life Technologies) supplemented with $10 \%$ fetal bovine serum (HyClone), antibiotics (Sigma-Aldrich), and L-glutamine (Corning) at $37^{\circ} \mathrm{C}$ and $5 \% \mathrm{CO}_{2}$ atmosphere.

Plasmids used in this study were obtained as follows: psPAX2 from Addgene (plasmid \#12260); pCMV14-3X-Flag-SARS-CoV-2-S from Addgene (plasmid \#145780); pFUGW-Pol2-ffLuc2-eGFP from Addgene (plasmid \#71394); pTwist-EF1Alpha-nCoV-2019-S-2xStrep, pLVX-EF1Alpha-SARS-CoV-2-M-2xStrep-IRES-Puro, and pLVXEF1Alpha-SARS-CoV-2-E-2xStrep-IRES-Puro from N. Krogan [University of California San Francisco (UCSF), USA]; pRRL-SFFVACE2-IRES-PURO and pRRL-SFFV-TMPRSS2-IRES-HYGRO from C. Goujon [Institut de Recherche en Infectiologie de Montpellier (IRIM), France]; pCAGGS-SARS2-S-NCflag D614 and pCAGGS-SARS2-SNCflag G614 from H. Choe (Scripps Research, USA); psPAX2 from Addgene (plasmid \#12260); and pCMV-VSV-G from P. Mageot [Center for Research in Infectious Diseases (CIRI), France].pNL4.3 $\Delta$ Env-F construct was obtained by removing the Renilla luciferase-coding region in the Spe I site present in the Gag coding region (1507 to 1512) of the previously described pNL4-3-RF reporter vector (40).

\section{Cell culture and generation of stable cell lines}

To generate stable HEK-ACE2-expressing cells, lentiviral particles were generated by cotransfecting $5 \times 10^{5}$ HEK293T cells with $3 \mu \mathrm{g}$ 
of psPAX2 packaging construct, $3 \mu \mathrm{g}$ of pCMV-VSV-G plasmid, and $3 \mu \mathrm{g}$ of lentiviral vector encoding for human ACE2 (pRRLSFFV-ACE2-IRES-PURO). Lentiviral vectors were collected 48 hours after transfection, cleared by centrifugation at $3000 \mathrm{rpm}$ for $5 \mathrm{~min}$ at room temperature, and used to transduce $293 \mathrm{~T}$ cells. Briefly, $2.5 \times 10^{5}$ HEK293T cells were treated with polybrene $(1 \mu \mathrm{g} / \mathrm{ml})$ for $45 \mathrm{~min}$ at $37^{\circ} \mathrm{C}$, and $50 \%$ of medium containing virus was added. HEK-ACE2 cells were subjected to puromycin $(1 \mu \mathrm{g} / \mathrm{ml}$; Sigma-Aldrich) selection (until control cells died) at 48 hours after transduction, and ACE2 expression was evaluated by Western blot.

\section{Western blot}

Cells were homogenized in a lysis buffer [ $50 \mathrm{mM}$ tris- $\mathrm{HCl}(\mathrm{pH} 7.4)$, $1 \%$ Triton X-100, and $20 \mathrm{mM}$ EDTA], vortexed, and stored at $-20^{\circ} \mathrm{C}$ overnight. Then, the cell lysate was centrifuged at $5000 \mathrm{rpm}$ for $5 \mathrm{~min}$ at $4^{\circ} \mathrm{C}$ to remove cell membranes, and proteins in the supernatant were quantified by Bradford assay (Bio-Rad). Proteins $(40 \mu \mathrm{g})$ were loaded into a 5 to $15 \%$ gradient gel and transferred to a nitrocellulose membrane for 2 hours at $400 \mathrm{~mA}$ at $4^{\circ} \mathrm{C}$. The membrane was incubated with the blocking solution (Bio-Rad) for 1 hour at room temperature, and primary antibodies for ACE2 (sc-73668), TMPRSS2 (sc-515727), Flag (F7425), Strep-tag (BL26882), and glyceraldehyde-3-phosphate dehydrogenase (sc-47724) were incubated overnight in 5\% blocking solution. Membranes were washed three times with Tris-buffered saline with $0.1 \%$ Tween 20 detergent (TBS-T), and secondary horseradish peroxidase (HRP)-conjugated antibodies (Jackson ImmunoResearch) in $0.5 \%$ blocking solution were incubated for 1 hour at room temperature. Last, chemiluminescence was detected by using the C-DiGit LI-COR system and the Image Studio Digits software.

\section{HIV-1-based SARS-CoV-2 pseudotype particles}

Pseudotyped viral particles were generated by cotransfection of HIV-1- $\Delta$ Env-FLuc vector and pCMV14-3X-Flag-SARS-CoV-2 S $\Delta 19 \mathrm{CT}$ (Addgene plasmid \#145780) (molar ratio, 1:1) by using linear polyethylenimine (PEI) prepared as described previously (53). HEK293T cells were transfected using a ratio $\mu \mathrm{g} D \mathrm{DN} / \mu \mathrm{PEI}$ of $1: 15$, and 24 hours after transfection, cells were washed and fresh media was added. The virus-containing supernatant was collected 24 hours after, and cellular debris was removed by centrifugation at $3000 \mathrm{rpm}$ for $5 \mathrm{~min}$ at room temperature. Viral stocks were diluted $50 \%$ in fetal bovine serum (Sigma-Aldrich), aliquoted, and stored at $-80^{\circ} \mathrm{C}$ for later use. The levels of viral particles in the cell supernatant were quantified using the HIV-1 Gag p24 Quantikine ELISA Kit (R\&D Systems) and titrated by serial dilution transduction of HEK-ACE2 cells in white 96-well plates (SPL Life Sciences). To do this, $1 \times 10^{4}$ cells per well were seeded in $100 \mu \mathrm{l}$ of DMEM, and eight 1:2 serial dilutions of the pseudotype in $100 \mu \mathrm{l}$ were added in triplicate. Forty-eight hours after transduction, media was removed and $25 \mu \mathrm{l}$ of $1 \times$ passive lysis buffer (Promega) was added to each well. Plates were incubated for $10 \mathrm{~min}$ at $400 \mathrm{rpm}$ at room temperature using the Synergy HTX Multi-Mode Microplate Reader (BioTek). Luciferase assay reagent ( $25 \mu$; Promega) at room temperature was added, and firefly luciferase activity was measured using the GloMax 96 Microplate Luminometer (Promega) after 5 s of integration and considering a 2-s delay between samples. These data were used to determine the dilution in which the luminescence reaches around 150,000 RLUs. In our system, the transduction of 3 to $5 \mathrm{pg}$ of p24 per well allowed us to obtain RLUs 100-folds over the background; thus, all the experiments were performed under these conditions.

\section{Three plasmid-based SARS-CoV-2 pseudotype particles}

To generate HIV-1-based lentiviral SARS-CoV-2 particles, three plasmids were used: the reporter vector (pFUGW-Pol2-ffLuc2-eGFP), HIV-1 structural/regulatory proteins (psPAX2), and the $\mathrm{S}$ coding plasmid (pCMV14-3X-Flag-SARS-CoV-2-S); these vectors were cotransfected, and lentiviral particles productions were performed as described above.

\section{Cell-cell fusion assays}

For cell-cell fusion assay, HEK293T cells were seeded in six-well plates and transfected with a 1:1 mixture of GFP and VSV-G or spike-coding plasmids. In parallel, HEK293T and HEK-ACE2 cells were seeded on $18-\mathrm{mm}$ coverslips and transfected with an mCherrycoding plasmid. At 48 hours after transfection, GFP and envelopeexpressing cells were washed and trypsinized, and an equal number of cells was added and mixed with the mCherry-expressing cells. Five hours later, cells were fixed with $4 \%$ paraformaldehyde (PFA) for $20 \mathrm{~min}$ at room temperature and incubated with $1 \times$ DAPI (4',6-diamidino-2-phenylindole) for $3 \mathrm{~min}$. Images were acquired with an IX73 Olympus Microscope.

\section{Immunofluorescence}

HEK293T cells $\left(8 \times 10^{4}\right.$ cells per well) were seeded on $18-\mathrm{mm}$ coverslips and transfected with a 1:0.5 ratio of $S: M$ or $S: E$ vectors using PEI as described above. The pCDNA 3.1 plasmid was used to balance the amount of transfected DNA in each well. At 48 hours after transfection, cells were fixed with $4 \%$ PFA for $20 \mathrm{~min}$ at room temperature, permeabilized for 5 min with $0.02 \%$ Triton X-100, and incubated for $30 \mathrm{~min}$ in blocking solution. Primary antibodies, rabbit anti-Flag (F7425), and mouse anti-Strep-tag (BL26882) diluted 1:200 were incubated for 2 hours at room temperature. After two washes in phosphate-buffered saline (PBS), secondary Alexa Fluor-conjugated antibodies (donkey anti-mouse 647 and donkey anti-rabbit 488) diluted 1:500 were incubated for 1 hour at room temperature. Cells were then washed and incubated in $1 \times$ DAPI for $3 \mathrm{~min}$, and last, images were acquired with an Axio Observer 5 microscope (Zeiss) using the $40 \times$ objective and analyzed using the ZEN software.

\section{Endocytosis inhibition}

HEK-ACE2 cells were plated in 96-well plates and treated with $20 \mathrm{mM} \mathrm{NH}_{4} \mathrm{Cl}$ for 1 hour at $37^{\circ} \mathrm{C}$. Then, cells were infected by spinoculation at $1200 \mathrm{~g}$ for $30 \mathrm{~min}$ at room temperature, and firefly activity was evaluated 48 hours later as described above.

\section{Patient recruitment and sample collection}

Regular blood bank donors consented to donate plasma and serum for IgG and NAb analysis. Two groups of healthy samples were considered: plasma from a regular blood donation obtained before October 2019 and a single blood drawn in April 2020 from asymptomatic healthy volunteers with a negative SARS-CoV-2 real-time PCR result.

Sick volunteers were consented at the moment of hospitalization and met the following inclusion criteria: patients over 18 years old, COVID-19 diagnosis at enrolment confirmed with a positive SARSCoV-2 PCR in nasopharyngeal swab, and candidate for convalescent plasma transfusion (NCT04384588 or NCT04375098). Recovered volunteers and convalescent plasma donors signed a consent letter as part of the clinical trial NCT04384588. All volunteer patients 
recovered from COVID-19, were asymptomatic for at least 28 days, and showed a negative result for the SARS-CoV-2 PCR test.

All participants were tested by ELISA for anti-SARS-CoV-2 (S1) IgG titers, as well as for standard infectious diseases (hepatitis B virus, hepatitis $\mathrm{C}$ virus, HIV, human T cell leukemia virus I/II, and Trypanosoma cruzi and Treponema pallidum serologies), and, for the plasma to be transfused, was also tested by nucleic acid amplification test (NAAT) for HIV, hepatitis B, and hepatitis $\mathrm{C}$ viruses. For details regarding the criteria for plasma transfusion, please review the information at www.clinicaltrials.gov for each trial (NCT04384588 and NCT04375098).

Four groups of healthy samples from Pontificia Universidad Católica de Chile were considered: (i) plasma from a regular blood donation obtained before October 2019; (ii) a single blood drawn in April 2020 from asymptomatic healthy volunteers with a negative SARS-CoV-2 real-time PCR result; (iii) 12 serum samples from 2012, obtained under hantavirus project close household contacts (NIH: no. U01AI055452); and (iv) a single blood drawn in June 2020 from asymptomatic healthy volunteers with negative IgG for SARS-CoV-2 (ELISA S-based assay, Euroimmun).

\section{Quantitative IgG ELISA anti-RBD S1 SARS-CoV-2}

An in-house quantitative and indirect ELISA test was developed and validated. Briefly, microplates 96-well MaxiSorp (439454, Nunc, Thermo Fisher Scientific) covered with $50 \mathrm{ng}$ of S1-RBD protein from SARS-CoV-2 (RB.230-30162-100, RayBiotech) were used for IgG detection. Serum samples were diluted in bovine serum albumin $0.1 \%$ in PBS and incubated for 1 hour at room temperature. In parallel, negative and positive serum controls were used. A calibration curve from 0 to $250 \mathrm{ng} / \mathrm{ml}$ was included using as a standard material, a commercial chimeric mouse scFv fusion with human IgG1 Fc antiSARS-CoV-2-S1-RBD (CSB-YP3324GMY1, Cusabio). Human serum IgG was detected using an HRP-conjugated donkey anti-human IgG diluted at $20 \mathrm{ng} / \mathrm{ml}$ and incubated for 1 hour at room temperature, and the reaction was developed using 3,3',5,5'-tetramethylbenzidine liquid substrate (T0440, Sigma-Aldrich). The reaction was stopped with $2 \mathrm{M}$ sulfuric acid, and the formed yellow reaction product was measured at $450 \mathrm{~nm}$ within the first $30 \mathrm{~min}$ in a Cytation5 plate reader (BioTek). The IgG concentration was estimated from the calibration curve. Blank and controls were performed within their respective $5 \%$ coefficient of variation $(\mathrm{CV})$.

\section{Pseudovirus neutralization assay}

Serum samples were incubated at $56^{\circ} \mathrm{C}$ for $30 \mathrm{~min}$ and stored at $4^{\circ} \mathrm{C}$ until use. For neutralization assays, samples were diluted in DMEM and $50 \mu$ l of the dilution was added to each well in triplicate. Pseudotype stocks were thawed on ice and diluted to obtain 3 to 5 pg of p24 in $50 \mu \mathrm{l}$ of DMEM and was added to each well of 96 -well plates. The mix (50\% sample and 50\% virus) was incubated for 1 hour at $37^{\circ} \mathrm{C}$. As a positive control, $50 \mu \mathrm{l}$ of the pseudotype (100\% infectivity) was incubated with $50 \mu \mathrm{l}$ of DMEM. Then, $1 \times 10^{4}$ of HEK-ACE2 cells in $100 \mu \mathrm{l}$ were added to each well, and HEK293T cells transduced with the pseudotype were used as a negative control $(0 \%$ infectivity). Firefly luciferase activity was measured 48 hours later as indicated above. Neutralizing assays were validated considering the following pass/fail criteria: (i) The average RLU from the pseudovirus control wells is $\geq 10$ times the average RLU of the negative control wells (HEK293T cells). (ii) The CV between RLU in the pseudotype control wells is $\leq 30 \%$. (iii) The percent difference for triplicate wells is $\leq 30 \%$ for sample dilutions that yield at least $40 \%$ neutralization. (iv) Positive control neutralization curve crosses the $50 \%$ neutralization cutoff 0 to 1 times.

\section{SARS-CoV-2 neutralization assay}

All the procedures handling the SARS-CoV-2 and infected cell cultures were held at the BSL-3 laboratory under protocol approved by Institutional Biosafety Committee from the Pontificia Universidad Católica de Chile. Vero-E6 cells were used for both the isolation of SARS-CoV-2 and the neutralization assays. The cells were cultured in DMEM supplemented with penicillin $\mathrm{G}(100 \mathrm{U} / \mathrm{ml})$, streptomycin $(100 \mathrm{mg} / \mathrm{ml}), 2 \mathrm{mM}$ L-glutamine, and $10 \%$ heat-inactivated fetal bovine serum. All cell cultures were maintained in $5 \% \mathrm{CO}_{2}$ at $37^{\circ} \mathrm{C}$.

Neutralization assay were conducted as follows: 96 -well plate were seeded with 20,000 cells in $100 \mu \mathrm{l}$ of DMEM the day before neutralization assay. The next day, SARS-CoV-2 TCDI50 $3,5^{-3}$ was incubated with different serum dilution $(1: 40$ to $1: 5120)$ at $37^{\circ} \mathrm{C}$ for 1 hour. After, $100 \mu \mathrm{l}$ was added to Vero-E6 cell and incubated for 5 days (at the second day, the growth media was replaced), fixed with $4 \%$ PFA for $30 \mathrm{~min}$, and stained with 5\% crystal violet for $10 \mathrm{~min}$, which strain only living cells. The neutralization titer was expressed as reciprocal of the highest dilution at which infections was blocked. The neutralization assay at Instituto de Salud Pública was carried out in the BSL-3 laboratory at the Enfermedades Virales Subdepartment using serial serum dilutions from 1:40 to 1:1280 following an in-house protocol through infection of Vero-E6 cells and a SARS-CoV-2 isolate during 7 days.

\section{Sequences analysis}

Sequences of 228 SARS-CoV-2 genomes available on 24 November 2020 were downloaded from GISAID (www.gisaid.org). The genomes were aligned to the reference using nucmer, and singlenucleotide polymorphisms (SNPs) were predicted using nucmer tool show-snps. Then, the SNPs were annotated using SnpEff within the SARS-CoV-2 database. Using the SNP annotation, sequences from spike protein were reconstructed using in-house PERL scripts. These sequences were aligned using ClustalW, and the output was uploaded to WebLogo service to generate the amino acid position frequency plot. All the computations were run at the National Laboratory for High-Performance Computing (www.nlhpc.cl).

\section{Statistical analysis}

Comparisons between two clinical groups were performed through an unpaired two-tailed Mann-Whitney test. Sigmoid curves and estimation of the ID50 were obtained using a four-parameter nonlinear regression curve fit measured as the percent of neutralization determined by the difference in average relative light units (RLU) between test samples and pseudotyped virus controls. To obtain the ID50 values, the lack of fit test would have a $P$ value $>0.1$. The top values were constrained to 100 , and the bottom values were set to 0 . Correlations were analyzed by calculating Spearman's rank correlation coefficients. $P$ values of $\leq 0.05$ indicate statistical significance. All statistical analyses were performed using GraphPad Prism version 8.4.3 software.

\section{SUPPLEMENTARY MATERIALS}

Supplementary material for this article is available at http://advances.sciencemag.org/cgi/ content/full/7/7/eabe6855/DC1

View/request a protocol for this paper from Bio-protocol. 


\section{REFERENCES AND NOTES}

1. N. Zhu, D. Zhang, W. Wang, X. Li, B. Yang, J. Song, X. Zhao, B. Huang, W. Shi, R. Lu, P. Niu, F. Zhan, X. Ma, D. Wang, W. Xu, G. Wu, G. F. Gao, W. Tan; China Novel Coronavirus Investigating and Research Team, A novel coronavirus from patients with pneumonia in China, 2019. N. Engl. J. Med. 382, 727-733 (2020).

2. P. Zhou, X. Lou Yang, X. G. Wang, B. Hu, L. Zhang, W. Zhang, H. R. Si, Y. Zhu, B. Li, C. L. Huang, H. D. Chen, J. Chen, Y. Luo, H. Guo, R. Di Jiang, M. Q. Liu, Y. Chen, X. R. Shen, X. Wang, X. S. Zheng, K. Zhao, Q. J. Chen, F. Deng, L. L. Liu, B. Yan, F. X. Zhan, Y. Y. Wang, G. F. Xiao, Z. L. Shi, Addendum: A pneumonia outbreak associated with a new coronavirus of probable bat origin. Nature 579, 270-273 (2020)

3. COVID-19 Map_Johns Hopkins Coronavirus Resource Center; https://coronavirus.jhu. edu/map.html.

4. T. Burki, COVID-19 in Latin America. Lancet Infect. Dis. 20, 547-548 (2020).

5. A. E. Castillo, B. Parra, P. Tapia, A. Acevedo, J. Lagos, W. Andrade, L. Arata, G. Leal, G. Barra, C. Tambley, J. Tognarelli, P. Bustos, S. Ulloa, R. Fasce, J. Fernández, Phylogenetic analysis of the first four SARS-CoV-2 cases in Chile. J. Med. Virol. 92, 1562-1566 (2020).

6. Chart: COVID-19 Cases per Million Inhabitants: A Comparison Statista (2020); www. statista.com/chart/21176/covid-19-infection-density-in-countries-most-total-cases/.

7. P. Villalobos Dintrans, J. Browne, I. Madero-Cabib, It is not just mortality: A call from chile for comprehensive COVID-19 policy responses among older people. J. Gerontol. Ser. B 2020, gbaa092 (2020)

8. A. Pablos-Méndez, J. Vega, F. P. Aranguren, H. Tabish, M. C. Raviglione, Covid-19 in Latin America. BMJ 370, m2939 (2020)

9. O. Abu Hammad, A. Alnazzawi, S. S. Borzangy, A. Abu-Hammad, M. Fayad, S. Saadaledin S. Abu-Hammad, N. Dar Odeh, Factors influencing global variations in COVID-19 cases and fatalities; a review. Healthcare 8, 216 (2020).

10. D. R. Burton, L. M. Walker, Rational vaccine design in the time of COVID-19. Cell Host Microbe 27, 695-698 (2020)

11. A. Chandrashekar, J. Liu, A. J. Martino, K. McMahan, N. B. Mercad, L. Peter, L. H. Tostanosk, J. Yu, Z. Maliga, M. Nekorchuk, K. Busman-Sahay, M. Terry, L. M. Wriji, S. Ducat, D. R. Martine, C. Atyeo, S. Fischinger, J. S. Burk, M. D. Slei, L. Pessaint, A. Van Ry, J. Greenhouse, T. Taylor, K. Blade, A. Cook, B. Finneyfrock, R. Brown, E. Teow, J. Velasco, R. Zahn, F. Wegmann, P. Abbink, E. A. Bondzi, G. Dagotto, M. S. Gebr, X. He, C. Jacob-Dolan, N. Kordana, Z. Li, M. A. Lifto, S. H. Mahrokhia, L. F. Maxfiel, R. Nityanandam, J. P. Nkolol, A. G. Schmid, A. D. Mille, R. S. Bari, G. Alter, P. K. Sorge, J. D. Este, H. Andersen, M. G. Lewi, D. H. Barou, SARS-CoV-2 infection protects against rechallenge in rhesus macaques. Science 369, 812-817 (2020).

12. W. Deng, L. Bao, J. Liu, C. Xiao, J. Liu, J. Xue, Q. Lv, F. Qi, H. Gao, P. Yu, Y. Xu, Y. Qu, F. Li, Z. Xiang, H. Yu, S. Gong, M. Liu, G. Wang, S. Wang, Z. Song, Y. Liu, W. Zhao, Y. Han, L. Zhao, X. Liu, Q. Wei, C. Qin, Primary exposure to SARS-CoV-2 protects against reinfection in rhesus macaques. Science 369, 818-823 (2020)

13. T. F. Rogers, F. Zhao, D. Huang, N. Beutler, A. Burns, W. T. He, O. Limbo, C. Smith G. Song, J. Woehl, L. Yang, R. K. Abbott, S. Callaghan, E. Garcia, J. Hurtado, M. Parren, L. Peng, S. Ramirez, J. Ricketts, M. J. Ricciardi, S. A. Rawlings, N. C. Wu, M. Yuan, D. M. Smith, D. Nemazee, J. R. Teijaro, J. E. Voss, I. A. Wilson, R. Andrabi, B. Briney, E. Landais, D. Sok, J. G. Jardine, D. R. Burton, Isolation of potent SARS-CoV-2 neutralizing antibodies and protection from disease in a small animal model. Science 369, 956-963 (2020).

14. A. Baum, R. Copin, D. Ajithdoss, A. Zhou, K. Lanza, N. Negron, M. Ni, Y. Wei, G. S. Atwal A. Oyejide, Y. Goez-Gazi, J. Dutton, E. Clemmons, H. M. Staples, C. Bartley, B. Klaffke, K. Alfson, M. Gazi, O. Gonzales, E. Dick, R. Carrion, L. Pessaint, A. Cook, R. Brown, V. Ali, J. Greenhouse, T. Taylor, M. G. Lewis, N. Stahl, A. J. Murphy, G. D. Yancopoulos, A. Kyratsous, REGN-COV2 antibody cocktail prevents and treats SARS-CoV-2 infection in rhesus macaques and hamsters. bioRxiv 10.1101/2020.08.02.233320, (2020).

15. D. E. Speiser, M. F. Bachmann, Covid-19: Mechanisms of vaccination and immunity. Vaccine 8, 404 (2020)

16. J. Seow, C. Graham, B. Merrick, S. Acors, K. J. A. Steel, O. Hemmings, A. O'Bryne, N. Kouphou, S. Pickering, R. Galao, G. Betancor, H. D. Wilson, A. W. Signell, H. Winstone, C. Kerridge, N. Temperton, L. Snell, K. Bisnauthsing, A. Moore, A. Green, L. Martinez, B. Stokes, J. Honey, A. Izquierdo-Barras, G. Arbane, A. Patel, L. OConnell, G. O. Hara, E. MacMahon, S. Douthwaite, G. Nebbia, R. Batra, R. Martinez-Nunez, J. D. Edgeworth, S. J. D. Neil, M. H. Malim, K. Doores, Longitudinal evaluation and decline of antibody responses in SARS-CoV-2 infection. medRxiv 10.1101/2020.07.09.20148429, (2020).

17. L. Ni, F. Ye, M. L. Cheng, Y. Feng, Y. Q. Deng, H. Zhao, P. Wei, J. Ge, M. Gou, X. Li, L. Sun T. Cao, P. Wang, C. Zhou, R. Zhang, P. Liang, H. Guo, X. Wang, C. F. Qin, F. Chen, C. Dong, Detection of SARS-CoV-2-specific humoral and cellular immunity in COVID-19 convalescent individuals. Immunity 52, 971-977.e3 (2020).

18. C. Rydyznski Moderbacher, S. I. Ramirez, J. M. Dan, A. Grifoni, K. M. Hastie, D. Weiskopf, S. Belanger, R. K. Abbott, C. Kim, J. Choi, Y. Kato, E. G. Crotty, C. Kim, S. A. Rawlings, J. Mateus, L. P. V. Tse, A. Frazier, R. Baric, B. Peters, J. Greenbaum, E. Ollmann Saphire, D. M. Smith, A. Sette, S. Crotty, Antigen-specific adaptive immunity to SARS-CoV-2 in acute COVID-19 and associations with age and disease severity. Cell 183, 996-1012.e19 (2020).

19. J. M. Dan, J. Mateus, Y. Kato, K. M. Hastie, C. E. Faliti, S. I. Ramirez, A. Frazier, E. Dawen Yu, A. Grifoni, S. A. Rawlings, B. Peters, F. Krammer, V. Simon, E. Ollmann Saphire, D. M. Smith, D. Weiskopf, A. Sette, S. Crotty, Immunological memory to SARS-CoV-2 assessed for up to eight months after infection. bioRxiv 10.1101/2020.11.15.383323, (2020)

20. W. Li, M. J. Moore, N. Vasllieva, J. Sui, S. K. Wong, M. A. Berne, M. Somasundaran, J. L. Sullivan, K. Luzuriaga, T. C. Greeneugh, H. Choe, M. Farzan, Angiotensin-converting enzyme 2 is a functional receptor for the SARS coronavirus. Nature 426, 450-454 (2003).

21. M. Hoffmann, H. Kleine-Weber, S. Schroeder, N. Krüger, T. Herrler, S. Erichsen, T. S. Schiergens, G. Herrler, N. H. Wu, A. Nitsche, M. A. Müller, C. Drosten, S. Pöhlmann SARS-CoV-2 cell entry depends on ACE2 and TMPRSS2 and is blocked by a clinically proven protease inhibitor. Cell 181, 271-280.e8 (2020).

22. T. A. Bates, J. B. Weinstein, S. E. Farley, H. C. Leier, W. B. Messer, F. G. Tafesse, Crossreactivity of SARS-CoV structural protein antibodies against SARS-CoV-2. bioRxiv 10.1101/2020.07.30.229377, (2020)

23. S. K. Samrat, A. M. Tharappel, Z. Li, H. Li, Prospect of SARS-CoV-2 spike protein: Potential role in vaccine and therapeutic development. Virus Res. 288, 198141 (2020).

24. D. Weissman, M.-G. Alameh, C. C. LaBranche, L. Sutherland, S. Santra, K. Mansouri, S. Gobeil, C. McDanal, N. Pardi, P. A. Shaw, M. G. Lewis, U. Sahin, P. Acharya, B. F. Haynes, B. Korber, C. Montefiori, D614G spike mutation increases SARS CoV-2 susceptibility to neutralization. medRxiv 10.1101/2020.07.22.20159905, (2020).

25. L. Zhang, C. B. Jackson, H. Mou, A. Ojha, E. S. Rangarajan, T. Izard, M. Farzan, H. Choe, SARS-CoV-2 spike-protein D614G mutation increases virion spike density and infectivity. Nat. Commun. 11, 6013 (2020)

26. L. Yurkovetskiy, K. E. Pascal, C. Tompkins-Tinch, T. Nyalile, Y. Wang, A. Baum, W. E. Diehl, A. Dauphin, C. Carbone, K. Veinotte, S. B. Egri, S. F. Schaffner, J. E. Lemieux, J. Munro, P. C. Sabeti, C. Kyratsous, K. Shen, J. Luban, SARS-CoV-2 Spike protein variant D614G increases infectivity and retains sensitivity to antibodies that target the receptor binding domain. bioRxiv 2020.07.04.187757, (2020).

27. C. Klumpp-Thomas, H. Kalish, J. Hicks, J. Mehalko, M. Drew, M. Memoli, M. Hall, D. Esposito, K. Sadtler, D614G spike variant does not alter IgG, IgM, or IgA spike seroassay performance. medRxiv 10.1101/2020.07.08.20147371, (2020).

28. B. Wang, D. Asarnow, W.-H. Lee, C.-W. Huang, B. Faust, P. M. L. Ng, E. Z. X. Ngoh, M. Bohn, D. Bulkley, A. Pizzorno, H. C. Tan, C. Y. Lee, R. A. Minhat, O. Terrier, M. K. Soh, F. J. Teo, Y. Y. C. Yeap, Y. Hu, S. G. K. Seah, S. Maurer-Stroh, L. Renia, B. J. Hanson, M. Rosa-Calatrava, A. Manglik, Y. Cheng, C. Craik, C.-I. Wang, Bivalent binding of a fully human IgG to the SARS-CoV-2 spike proteins reveals mechanisms of potent neutralization. bioRxiv 10.1101/2020.07.14.203414, (2020)

29. Q. Li, J. Wu, J. Nie, X. Li, W. Huang, Y. W. Correspondence, The impact of mutations in SARS-CoV-2 spike on viral infectivity and antigenicity. Cell 182, 1284-1294.e9 (2020).

30. B. Korber, W. M. Fischer, S. Gnanakaran, H. Yoon, J. Theiler, W. Abfalterer, N. Hengartner, E. E. Giorgi, T. Bhattacharya, B. Foley, K. M. Hastie, M. D. Parker, D. G. Partridge, C. M. Evans, T. M. Freeman, T. I. de Silva, A. Angyal, R. L. Brown, L. Carrilero, L. R. Green D. C. Groves, K. J. Johnson, A. J. Keeley, B. B. Lindsey, P. J. Parsons, M. Raza, S. Rowland-Jones, N. Smith, R. M. Tucker, D. Wang, M. D. Wyles, C. McDanal, L. G. Perez, H. Tang, A. Moon-Walker, S. P. Whelan, C. C. LaBranche, E. O. Saphire, D. C. Montefiori, Tracking changes in SARS-CoV-2 spike: Evidence that D614G increases infectivity of the COVID-19 virus. Cell 182, 812-827.e19 (2020).

31. F. Schmidt, Y. Weisblum, F. Muecksch, H.-H. Hoffmann, E. Michailidis, J. C. C. Lorenzi, P. Mendoza, M. Rutkowska, E. Bednarski, C. Gaebler, M. Agudelo, A. Cho, Z. Wang, A. Gazumyan, M. Cipolla, M. Caskey, D. F. Robbiani, M. C. Nussenzweig, C. M. Rice T. Hatziioannou, P. D. Bieniasz, Measuring SARS-CoV-2 neutralizing antibody activity using pseudotyped and chimeric viruses. J. Exp. Med. 217, e20201181 (2020).

32. K. H. D. Crawford, R. Eguia, A. S. Dingens, A. N. Loes, K. D. Malone, C. R. Wolf, H. Y. Chu M. A. Tortorici, D. Veesler, M. Murphy, D. Pettie, N. P. King, A. B. Balazs, J. D. Bloom, Protocol and reagents for pseudotyping lentiviral particles with SARS-CoV-2 spike protein for neutralization assays. Viruses 12, 513 (2020).

33. J. Nie, Q. Li, J. Wu, C. Zhao, H. Hao, H. Liu, L. Zhang, L. Nie, H. Qin, M. Wang, Q. Lu, X. Li, Q. Sun, J. Liu, C. Fan, W. Huang, M. Xu, Y. Wang, Establishment and validation of a pseudovirus neutralization assay for SARS-CoV-2. Emerg. Microbes. Infect. 9, 680-686 (2020).

34. F. Zettl, T. L. Meister, T. Vollmer, B. Fischer, J. Steinmann, A. Krawczyk, P. V'kovski, D. Todt, E. Steinmann, S. Pfaender, G. Zimmer, Rapid quantification of SARS-CoV-2-neutralizing antibodies using propagation-defective vesicular stomatitis virus pseudotypes. Vaccine 8, 386 (2020).

35. Y. Zheng, E. T. Larragoite, J. Lama, I. Cisneros, J. Delgado, P. Slev, J. Rychert, M. Coiras, M. Rondina, A. M. Spivak, V. Planelles, Neutralization assay with SARS-CoV-1 and SARS-CoV-2 spike pseudotyped murine leukemia virions. bioRxiv 10.1101/2020.07.17.207563, (2020).

36. T. Giroglou, J. Cinatl, H. Rabenau, C. Drosten, H. Schwalbe, H. W. Doerr, D. von Laer, Retroviral vectors pseudotyped with severe acute respiratory syndrome coronavirus S protein. J. Virol. 78, 9007-9015 (2004). 
37. X. Ou, Y. Liu, X. Lei, P. Li, D. Mi, L. Ren, L. Guo, R. Guo, T. Chen, J. Hu, Z. Xiang, Z. Mu, X. Chen, J. Chen, K. Hu, Q. Jin, J. Wang, Z. Qian, Characterization of spike glycoprotein of SARS-CoV-2 on virus entry and its immune cross-reactivity with SARS-CoV. Nat. Commun. 11, 1620 (2020).

38. M. Burse, J. Shi, C. Aiken, Cyclophilin A potentiates TRIM5 $\alpha$ inhibition of HIV-1 nuclear import without promoting TRIM5 $\alpha$ binding to the viral capsid. PLOS ONE 12, e0182298 (2017).

39. K. Liao, D. Sikkema, C. Wang, T. N. Lee, Development of an enzymatic assay for the detection of neutralizing antibodies against therapeutic angiotensin-converting enzyme 2 (ACE2). J. Immunol. Methods 389, 52-60 (2013).

40. C. E. McBride, J. Li, C. E. Machamer, The cytoplasmic tail of the severe acute respiratory syndrome Coronavirus spike protein contains a novel endoplasmic reticulum retrieval signal that binds COPI and promotes interaction with membrane protein. J. Virol. 81, 2418-2428 (2007).

41. S. Ghosh, T. A. Dellibovi-Ragheb, A. Kerviel, E. Pak, Q. Qiu, M. Fisher, P. M. Takvorian, C. Bleck, V. W. Hsu, A. R. Fehr, S. Perlman, S. R. Achar, M. R. Straus, G. R. Whittaker, C. A. M. de Haan, J. Kehrl, G. Altan-Bonnet, N. Altan-Bonnet, $\beta$-Coronaviruses use lysosomes for egress instead of the biosynthetic secretory pathway. Cell 183, 1520-1535. e14 (2020).

42. L. Yurkovetskiy, X. Wang, K. E. Pascal, C. Tomkins-Tinch, T. Nyalile, Y. Wang, A. Baum, W. E. Diehl, A. Dauphin, C. Carbone, K. Veinotte, S. B. Egri, S. F. Schaffner, J. E. Lemieux, J. Munro, A. Rafique, A. Barve, P. C. Sabeti, C. A. Kyratsous, N. Dudkina, K. Shen, J. Luban, Structural and functional analysis of the D614G SARS-CoV-2 spike protein variant. Cell 183, 739-751.e8 (2020).

43. M. J. Joyner, J. W. Senefeld, S. A. Klassen, J. R. Mills, P. W. Johnson, E. S. Theel, C. C. Wiggins, K. A. Bruno, A. M. Klompas, K. L. Kunze, M. A. Sexton, J. C. D. Soto, S. E. Baker, J. R. Shepherd, N. van Helmond, S. Paneth, D. Fairweather, R. S. Wright, R. E. Carter, A. Casadevall, C. M. van Buskirk, J. R. Stubbs, R. F. Rea, D. O. Hodge, E. R. Whelan, A. J. Clayburn, K. F. Larson, J. G. Ripoll, K. J. Andersen, M. R. Buras, J. J. Dennis, R. J. Regimbal, P. R. Bauer, J. E. Blair, N. S. Paneth, D. Fairweather, R. S. Wright, R. E. Carter, A. Casadevall, Effect of convalescent plasma on mortality among hospitalized patients with COVID-19: Initial three-month experience. medRxiv 10.1101/2020.08.12.20169359, (2020).

44. COVID19-Convalescent Plasma for Treating Patients With Active Symptomatic COVID 19 Infection (FALP-COVID) (2020); https://clinicaltrials.gov/ct2/show/NCT04384588.

45. J. Lu, G. Lu, S. Tan, J. Xia, H. Xiong, X. Yu, Q. Qi, X. Yu, L. Li, H. Yu, N. Xia, T. Zhang, Y. Xu, J. Lin, A COVID-19 mRNA vaccine encoding SARS-CoV-2 virus-like particles induces a strong antiviral-like immune response in mice. Cell Res. 30, 936-939 (2020).

46. R. Zhou, K. K. W. To, Y. C. Wong, L. Liu, B. Zhou, X. Li, H. Huang, Y. Mo, T. Y. Luk, T. T. K. Lau, P. Yeung, W. M. Chan, A. K. L. Wu, K. C. Lung, O. T. Y. Tsang, W. S. Leung, I. F. N. Hung, K. Y. Yuen, Z. Chen, Acute SARS-CoV-2 infection impairs dendritic cell and T cell responses. Immunity 53, 864-877.e5 (2020).

47. F. Wu, M. Liu, A. Wang, L. Lu, Q. Wang, C. Gu, J. Chen, Y. Wu, S. Xia, Y. Ling, Y. Zhang, J. Xun, R. Zhang, Y. Xie, S. Jiang, T. Zhu, H. Lu, Y. Wen, J. Huang, Evaluating the association of clinical characteristics with neutralizing antibody levels in patients who have recovered from mild COVID-19 in Shanghai, China. JAMA Intern. Med. 180, 1356-1362 (2020).

48. D. Pinto, Y. J. Park, M. Beltramello, A. C. Walls, M. A. Tortorici, S. Bianchi, S. Jaconi, K. Culap, F. Zatta, A. De Marco, A. Peter, B. Guarino, R. Spreafico, E. Cameroni, J. B. Case, R. E. Chen, C. Havenar-Daughton, G. Snell, A. Telenti, H. W. Virgin, A. Lanzavecchia, M. S. Diamond, K. Fink, D. Veesler, D. Corti, Cross-neutralization of SARS-CoV-2 by a human monoclonal SARS-CoV antibody. Nature 583, 290-295 (2020).

49. R. W. Cross, A. N. Prasad, V. Borisevich, C. Woolsey, K. N. Agans, D. J. Deer, N. S. Dobias, J. B. Geisbert, K. A. Fenton, T. W. Geisbert, Use of convalescent serum reduces severity of COVID-19 in nonhuman primates. bioRxiv 10.1101/2020.10.14.340091, (2020).

50. M. R. Salazar, S. E. González, L. Regairaz, N. S. Ferrando, V. V. G. Martínez, P. M. C. Ramos, L. Muñoz, S. A. Pesci, J. M. Vidal, N. Kreplak, E. Estenssoro, Effect of convalescent plasma on mortality in patients with COVID-19 pneumonia. medRxiv 10.1101/2020.10.08.20202606, (2020).

51. R. Libster, G. P. Marc, D. Wappner, S. Coviello, A. Bianchi, V. Braem, I. Esteban, M. T. Caballero, C. Wood, M. Berrueta, A. Rondan, G. Lescano, P. Cruz, Y. Ritou, V. F. Viña, D. Á. Paggi, S. Esperante, A. Ferreti, G. Ofman, Á. Ciganda, R. Rodriguez, J. Lantos, R. Valentini, N. Itcovici, A. Hintze, M. L. Oyarvide, C. Etchegaray, A. Neira, I. Name, J. Alfonso, R. L. Castelo, G. Caruso, S. Rapelius, F. Alvez, F. Etchenique, F. Dimase,
D. Alvarez, S. Aranda, C. S. Yanotti, J. De Luca, S. J. Baviglio, S. Laudanno, F. Nowogrodzki, R. Larrea, M. Silveyra, G. Leberzstein, A. Debonis, J. Molinos, M. González, E. Perez, N. Kreplak, S. P. Argüello, L. Gibbons, F. Althabe, E. Bergel, F. P. Polack; Fundación INFANTCOVID-19 Group, Prevention of severe COVID-19 in the elderly by early high-titer plasma. medRxiv 10.1101/2020.11.20.20234013, (2020).

52. Y. Maor, D. Cohen, N. Paran, T. Israely, V. Ezra, O. Axelrod, E. Shinar, M. Izak, G. Rahav, N. Rahimi-Levene, B. M. Bazofin, R. Gelman, D. Dicker, T. Brosh-Nissimov, O. Megged, D. Dahan, A. Benov, A. Paz, K. Edward, A. Moran, O. Rogowski, P. Sorkine, A. Mayo, O. Zimhony, J. Chen, Compassionate use of convalescent plasma for treatment of moderate and severe pneumonia in COVID-19 patients and association with IgG antibody levels in donated plasma. EClinicalMedicine. 26, 100525 (2020).

53. A. Fröhlich, B. Rojas-Araya, C. Pereira-Montecinos, A. Dellarossa, D. Toro-Ascuy, Y. Prades-Pérez, F. García-de-Gracia, A. Garcés-Alday, P. S. Rubilar, F. Valiente-Echeverría, T. Ohlmann, R. Soto-Rifo, DEAD-box RNA helicase DDX3 connects CRM1-dependent nuclear export and translation of the HIV-1 unspliced mRNA through its N-terminal domain. Biochim. Biophys. Acta Gene Regul. Mech. 1859, 719-730 (2016).

Acknowledgments: We to thank C. Goujon (IRIM, France), H. Choe (Scripps Research, USA), N. Krogan (UCSF, USA), N. Tischler (Fundación Ciencia y Vida, Chile), and the NIH AIDS Reagents Program for providing some of the plasmids and cell lines used in this study. Funding: This work was funded by the FONDECYT Program through grants no. 1190156 (to R.S.-R.), no. 1180798 (to F.V.-E.), no. 1171570 (to M.E.B.), UCH-1566 (to C.B.-P.), NIH no. U01AI055452 (to M.F.), and ANID-COVID no. 0920 (to N.L.C.); Fondo de Adopción Tecnológica SiEmpre, SOFOFA Hub and Ministerio de Ciencia, Tecnología, Conocimiento e Innovación (to R.S.-R., F.V.-E., N.L.C., M.F., and M.E.B.); and a joint grant from SOFOFA, CPC, and Cámara de Comercio de Santiago to Fundación Arturo López Pérez Cancer Center. The Center for Mathematical Modeling (UMI CNRS 2807) is funded by a Basal Grant AFB-170001, and the Center for Genome Regulation is funded through Fondap Grant 15090007. Powered@NLHPC: This research was partially supported by the supercomputing infrastructure of the NLHPC (grant number ECM-02). Ethics statement: Samples collection at Fundación Arturo López Pérez Cancer Center was performed under the protocol FALP-001-2020 approved by the internal Ethic and Scientific Committee. Samples collection at Pontificia Universidad Católica de Chile was performed under the protocol approved by the Comité Etico Centifico de Ciencias de la Salud, Facultad de Medicina, Pontificia Universidad Católica de Chile (08086/16092/ 200416002/200415015/200513023). Human sample manipulation at the Laboratory of Molecular and Cellular Virology was approved under the protocol no. 096-2020 by the Ethics Committee for Research in Human Beings at Universidad de Chile Faculty of Medicine. Samples used in this study were anonymized. Authors contributions: C.B.-P., F.V.-E., and R.S.-R. performed the study design. C.B.-P., S.R.-B., A.O.-A., and A.G.-A. performed most of the experiments. F.V., R.G.-S., K.C.-S., and A.A. collected samples, performed apheresis, and the RBD-IgG ELISA. N.L.C., M.F., M.E.B., and C.M.-V. recruited patients and collected samples. C.M.-V. performed classical neutralization assays at Pontificia Universidad Católica de Chile. E.R. and J.F. performed classical neutralization assays at Instituto de Salud Pública de Chile. D.T. and R.P.-V. assembled sequences of SARS-CoV-2 isolates in the context of the Cov2.cl initiative and performed sequence analyses. A.G. and G.P.B. contributed to the study design. C.B.-P. and R.S.-R. wrote the manuscript. All authors read, commented on, and approved the final version of the manuscript. Competing interests: The authors declare that they have no competing interests. Data and material availability: Plasmids and cell lines generated in this study are fully available for research use through a material transfer agreement with Universidad de Chile. All data needed to evaluate the conclusions in the paper are present in the paper and/or the Supplementary Materials. Additional data related to this paper may be requested from the authors.

Submitted 8 September 2020 Accepted 23 December 2020 Published 12 February 2021 10.1126/sciadv.abe6855

Citation: C. Beltrán-Pavez, S. Riquelme-Barrios, A. Oyarzún-Arrau, A. Gaete-Argel, R. González-Stegmaier, K. Cereceda-Solis, A. Aguirre, D. Travisany, R. Palma-Vejares, G. P. Barriga, A. Gaggero, C. Martínez-Valdebenito, N. L. Corre, M. Ferrés, M. E. Balcells, J. Fernandez, E. Ramírez, F. Villarroel, F. Valiente-Echeverría, R. Soto-Rifo, Insights into neutralizing antibody responses in individuals exposed to SARS-CoV-2 in Chile. Sci. Adv. 7, eabe6855 (2021). 